\title{
Characteristics of Emissions from a Portable Two-stroke Gasoline Engine
}

\author{
Jen-Hsiung Tsai ${ }^{1}$, Yue-Rou Chen ${ }^{1}$, Shui-Jen Chen ${ }^{1 *}$, Sheng-Lun Lin ${ }^{2,3,4}$, Kuo-Lin Huang ${ }^{1}$, \\ Chih-Chung Lin ${ }^{1}$, Jue-Iyu Chiu ${ }^{1}$
}

${ }^{1}$ Department of Environmental Science and Engineering, National Pingtung University of Science and Technology, Pingtung 91201, Taiwan

${ }^{2}$ Department of Civil Engineering and Geomatics, Cheng Shiu University, Kaohsiung 83347, Taiwan

${ }^{3}$ Center for Environmental Toxin and Emerging-Contaminant Research, Cheng Shiu University, Kaohsiung 83347, Taiwan

${ }^{4}$ Super Micro Mass Research and Technology Center, Cheng Shiu University, Kaohsiung 83347, Taiwan

\begin{abstract}
This work investigates the engine performance and emission characteristics of a portable two-stroke gasoline engine (P2SGE) fueled by unleaded gasoline \#92 blended with different 2-stroke engine oil brands (CPC Super Low Smoke TwoStroke Engine Oil (SLS), CPC Low Smoke Two-Stroke Engine Oil (LS), and MERCURY STAR Two-Stroke Engine Oil (MS)) and operated at idling $(0 \mathrm{~kW})$, medium $(1.5 \mathrm{~kW})$ and high load $(1.9 \mathrm{~kW})$. Experimental results indicate that the emission factors (EFs) of HC and CO decreased with rising P2SGE load when each of the lubricants was used in the gasoline engine, while that of $\mathrm{NO}_{\mathrm{x}}$ exhibited an opposite trend. Using different brands of two-stroke engine oil did not influence the fuel consumption (FC) or specific fuel consumption (SFC) of P2SGE under the same engine speed. The mass concentrations and EFs of PM when adding the tested three lubricants were in the order MS $>$ SLS $>$ LS at all loads. $85 \%$ of the PM mass emitted from the P2SGE was contributed by carbonaceous matters (EC and OC) in all test conditions. The EFs based on the FC and output energy of PM-bound OC were higher than those of EC at idling condition, while an opposite trend (OC < EC) was observed at the medium $(1.5 \mathrm{~kW})$ and high $(1.9 \mathrm{~kW})$ engine loads. Additionally, the ratio of OC/EC decreased with increasing engine load, regardless of the difference in 2-stroke engine oil composition. Nap and PA dominated in the mass concentration among 16 investigated $\mathrm{PAH}$ homologs, while $\mathrm{BaP}$ and $\mathrm{BaA}$ mainly contributed the $\mathrm{BaP}_{\mathrm{eq}}$ concentrations, except using LS at high-load operation. Compared to the use of MS, the reductions of $\Sigma$ PAHs and $\Sigma B_{\text {Ba }}$ eq concentrations were $46.4 \%$ and $54.8 \%$, respectively for using SLS, and $59.7 \%$ and $49.2 \%$, respectively for using LS.
\end{abstract}

Keywords: Two-stroke gasoline engine, PM, Carbons, Polycyclic aromatic hydrocarbons.

\section{INTRODUCTION}

Environmental greening (such as park green space and planting) is a critical construction project in metropolitan cities around the world. In the maintenance of green landscapes, small or light engine powered apparatuses are often adopted to save human resources and increase work efficiency. However, these devices (such as mowers and leaf blowers) must be lightweight to reduce the cost in production, so they are often equipped with portable two-stroke gasoline engines (P2SGE), which have almost no exhaust gas treatment equipment. This fact generally results in the emission of large amounts of air pollutants, including carbon dioxide $\left(\mathrm{CO}_{2}\right)$, volatile organic compounds (VOCs), polycyclic aromatic

\footnotetext{
* Corresponding author.

Tel.: +886-8-7740263; Fax: +886-8-7740256

E-mail address: chensj@mail.npust.edu.tw
}

hydrocarbons (PAHs) and other harmful substances (Volckens et al., 2007; Shipchandler, 2008; Volckens et al., 2008; Chuang et al., 2010; Michaels, 2012; Dhital et al., 2019; Tsai et al., 2019). These compounds emitted from P2SGEs have been of little concerned until recently.

Gasoline engines have smaller sizes and weights than diesel engines, and vibrate less during operation, making them suitable for use in different types of high-speed rotation engines, such as motorcycles and lawnmowers. In general, gasoline engines are divided into two types: 2-stroke gasoline engines (2SGE) and 4-stroke gasoline engines (4SGE). Unlike in a 4SGE, the intake of air and the discharge of exhaust occur at the same time in a $2 \mathrm{SGE}$, leading to higher levels of unburned fuel vapor and other incomplete combustion matters in the exhaust. Moreover, the gasoline in a $2 \mathrm{SGE}$, must be blended with an appropriate proportion (approximately 3-5 vol.\%) of 2-cycle engine oil (lubricant) which is metal-enriched to lubricate and protect the engine parts. Unfortunately, the added 2-cycle engine oil is frequently hard to be entirely burned in such a short time in the 
combustion chamber; consequently, a 2SGE usually has higher emissions of air pollutants (e.g., $\mathrm{PM}_{2.5}$, elemental carbon (EC), organic carbon (OC), water-soluble ions and toxic metals (Jiang et al., 2017; Hao et al., 2019; Yang et al., 2019)) than a 4SGE under the same piston displacement. Therefore, countries are gradually banning on-road 2SGEs. For example, on-road 2SGEs have been banned in Europe and the United States, and their use is prohibited in several China's major cities now. Taiwan is expected to embargo driving 2SGEs on the streets from 2020. However, little attention has been paid to the emissions standards for offroad 2SGE.

Horticultural gasoline-powered equipment (HGPE) is frequently and widely employed for gardening in public spaces such as schools and parks. However, HGPEs yield high levels of air pollutants during operation, which exposes operators and nearby people to such injurious environments and increases their health risks (Banks and McConnell, 2015). Banks and McConnell (2015) also indicated that there were approximately 121 million items of HGPEs in the United States in 2011, of which more than one-third were lawnmowers, followed by trimmers, edgers, brush cutters, leaf blowers and vacuums in order. According to the U.S. Environmental Protection Agency (U.S. EPA, 2017), about 54 million Americans use HGPEs for their garden planting and lawn maintenance every weekend, thus consuming about 800 million gallons of gasoline per year. Carbon monoxide (CO), VOCs and nitrogen oxides $\left(\mathrm{NO}_{\mathrm{x}}\right)$ emitted from these engines are thought to contribute around $5 \%$ of the nation's air pollution. Additionally, the operation of a new gasolinepowered lawnmower for an hour releases about the same quantities of VOCs and $\mathrm{NO}_{\mathrm{x}}$ as 11 new automobiles running for an hour. The exhausts emitted from gasoline and diesel vehicles have been confirmed as one of the primary emission sources causing poor air quality in the urban areas (Gehrig et al., 2001; Zhu et al., 2002; Lin et al., 2005, 2008; Grivas et al., 2018; Xiang et al., 2018; Wang et al., 2018).

P2SGEs are commonly fueled with two-cycle engine oil/gasoline mixtures, without exhaust-control devices, and even lack routine maintenance, and therefore emit more pollutants than regular gasoline vehicle engines. Nevertheless, the characteristics of emissions from P2SGE have not been extensively studied so far. Research has demonstrated that exposure to $\mathrm{PM}_{2.5}$ will cause anxiety symptoms, which may get worse when exposed to a higher $\mathrm{PM}_{2.5}$ concentration or closer emission source (Power et al., 2015; Zhang et al., 2018). In order to investigate the emission characteristics of P2SGE, this investigation utilized a small commonly used sprayer (KAWAGOE, C12E) as a testing engine. To prepare fuels for testing, unleaded gasoline \#92 was used as the base oil to blend (4 vol. $\%$ engine oil +96 vol. $\%$ gasoline) with one of three two-cycle engine oil brands: CPC Super Low Smoke Two-Stroke Engine Oil (SLS), CPC Low Smoke TwoStroke Engine Oil (LS), and MERCURY STAR Two-Stroke Engine Oil (MS). The emissions of particulate matter (PM), particle-bound carbonaceous species, PAHs (gas-phase + particle-phase) and gaseous pollutants, and even fuel consumption (FC) and engine power were measured at various engine loads (speeds).

\section{MATERIALS AND METHODS}

\section{Two-stroke Gasoline Engine, Test Fuels and Sampling Procedures}

This study selected as the test object a small portable gasoline-powered sprayer (KAWAGOE, Model: C12E), equipped with a single-cylinder, naturally aspirated, and aircooled two-stroke gasoline engine (Model: G45H; manufactured by Chaang Cherng Co., Ltd., TAIWAN); the cylinder displacement is 41.5 c.c., and the maximum horsepower is $2.2 \mathrm{ps}$. The base oil-unleaded gasoline \#92 used in this investigation was purchased from CPC (Chinese Petroleum Corporation) in Taiwan. Three 2-stroke engine oils were used: CPC Super Low Smoke Two-Stroke Engine Oil (SLS), CPC Low Smoke Two-Stroke Engine Oil (LS), and MERCURY STAR Two-Stroke Engine Oil (MS). Table 1 shows the properties of these 2-stroke engine oils.

The flue sampling equipment adopted in this work referred to U.S. EPA Method 5. Before starting the sampling, the exhaust gas flow velocity of the engine was measured using an S-type Pitot tube. After converting the flow rate, a constant flow sampling system equipped with a $47 \mathrm{~mm}$ dia. quartz fiber filter (Pallflex Tissuqartz 2500QAT-UP) was installed downstream of the P2SGE's exhaust to gather the particlephase samples. Gas-phase PAH samples were collected by two connected cartridges, each of which was packed with around

Table 1. The characteristics of 2-stroke engine oils.

\begin{tabular}{llllll}
\hline \multirow{2}{*}{ Test Item } & \multirow{2}{*}{ Unit } & \multicolumn{3}{c}{ 2-stroke engine oils } & \multirow{2}{*}{ Method } \\
\cline { 3 - 5 } & & SLS & LS & MS & \\
\hline Kinematic Viscosity $@ 40^{\circ} \mathrm{C}$ & $\mathrm{cSt}$ & 52.73 & 48.46 & 62.47 & ASTM D445-17a \\
Kinematic Viscosity $@ 100^{\circ} \mathrm{C}$ & $\mathrm{cSt}$ & 8.20 & 7.83 & 8.90 & ASTM D445-17a \\
Viscosity Index & - & 127 & 129 & 118 & ASTM D2270-10(2016) \\
Specific Gravity $@ 15.6^{\circ} \mathrm{C}$ & - & 0.8645 & 0.8680 & 0.8682 & ASTM D4052-18a \\
Sulfate Ash & $\mathrm{wt} \%$ & 0.13 & 0.15 & 0.01 & ASTM D874-13a(2018) \\
Total Acid Number & $\mathrm{mg} \mathrm{KOH} \mathrm{g}{ }^{-1}$ & 0.43 & 0.46 & 0.22 & ASTM D664A-18 \\
Total Base Number & $\mathrm{mg} \mathrm{KOH} \mathrm{g}{ }^{-1}$ & 2.7 & 2.8 & 0.46 & ASTM D2896B-15 \\
Carobn Residue, Rams & $\mathrm{wt} \%$ & 0.28 & 0.27 & 0.05 & ASTM D524-15 \\
Flash Point & ${ }^{\circ} \mathrm{C}$ & 94 & 98 & 136 & ASTM D92-18 \\
Pour Point & ${ }^{\circ} \mathrm{C}$ & -27 & -15 & -24 & ASTM D97-17b \\
\hline
\end{tabular}

-: Unavailable. 
30-35 g of XAD-2 resin, supported by two polyurethane foam (PUF) plugs. Tests of particle and PAH emissions were performed at rotating speeds of 3,800 rpm (idling), 5,000 rpm, and 7,000 rpm of the P2SGE fed with three fuel types. For each combination of parameters, the experiments were performed three times (each sampling time $=15 \mathrm{~min}$ ). Sampling data were accumulated after the engine had been run for at least $10 \mathrm{~min}$.

The quartz filters were pretreated before sampling by heating them in a muffle furnace in air for $2.5 \mathrm{~h}$ at $900^{\circ} \mathrm{C}$. The filters were dried for $24 \mathrm{~h}$ in a desiccator at $25 \pm 1{ }^{\circ} \mathrm{C}$ temperature and $40 \pm 5 \%$ relative humidity before and after each sampling. They were then weighed on an electronic seven-digit balance (UMX2, Mettler Toledo) with a resolution of $0.1 \mu \mathrm{g}$.

\section{$\mathrm{HC}, \mathrm{CO}$, and $\mathrm{NO}_{x}$ Emissions Analysis}

A portable gaseous pollutant analyzer (E8500 Plus; E Instruments, USA) was applied to monitor online hydrocarbon $(\mathrm{HC})$, carbon monoxide $(\mathrm{CO})$, and nitrogen oxide $\left(\mathrm{NO}_{\mathrm{x}}\right)$ emissions in the exhaust tailpipe. The E8500 Plus measured $\mathrm{NO}_{x}$ concentrations using an electrochemical detector with a concentration range of $0-5,000 \mathrm{ppm}$ ( $1 \mathrm{ppm}$ resolution and $4 \%$ relative accuracy), while $\mathrm{HC}$ and $\mathrm{CO}$ were measured by a non-dispersive infrared (NDIR) analyzer with concentration ranges $0-3$ vol. $\%(0.01 \%$ resolution and $3 \%$ relative accuracy) and $0-15$ vol. $\%$ ( $0.01 \%$ resolution and $3 \%$ relative accuracy), respectively.

\section{Carbonaceous Component Analysis}

The contents of particle-bound carbonaceous matters collected by the quartz filters were analyzed by a CHN-ORapid elemental analyzer (Model: 2400, Perkin Elmer Company, USA). Acetanilide ( $\mathrm{N}=10.36 \%, \mathrm{C}=71.09 \%, \mathrm{H}$ $=6.71 \%, \mathrm{O}=11.80 \%$ ) was adopted as the standard to prepare the calibration curve. Analysis conditions consisted of heating for $1.5 \mathrm{~min}$ with an oxidation tube temperature of $950^{\circ} \mathrm{C}$ and a reduction tube temperature of $600^{\circ} \mathrm{C}$. An NDIR detector was utilized to detect the $\mathrm{CO}_{2}$ content carried by helium after heat treatment. Finally, data were processed and the carbon content of a sample was obtained. However, organic carbon (OC) was not directly obtained by the EA. Therefore, one quarter of each filter was heated in an oven at $350^{\circ} \mathrm{C}$ for $100 \mathrm{~min}$ to eliminate the $\mathrm{OC}$ content, and was then placed in the elemental analyzer to determine the elemental carbon (EC) content; another quarter of each filter was then fed directly into the elemental analyzer without pre-treatment to measure the total carbon (TC) content. Accordingly, OC was then determined by subtracting EC from TC: $\mathrm{OC}=\mathrm{TC}-\mathrm{EC}$.

\section{PAH Analysis}

The gas-/particle-phase PAH samples accumulated from the P2SGE exhausts were extracted using 1:1 (volume ratio) $n$-hexane/dichloromethane for $24 \mathrm{hr}$. The extracts were then concentrated, cleaned by a silica column of $\sim 27 \mathrm{~cm}$ silica gel particles (size range $=0.04-0.063 \mathrm{~mm}$ ) under a layer of anhydrous $\mathrm{Na}_{2} \mathrm{SO}_{4}(\sim 1 \mathrm{~cm}$ high $)$ and above a support of glass fibers, and re-concentrated by purging with ultra-pure nitrogen to exactly $1.0 \mathrm{~mL}$ for the subsequent identification of 16 PAHs by a gas chromatograph/mass selective detector (GC/MSD; model: GC 6890N/HP 5973). The GC/MSD, equipped with a capillary column (HP Ultra 2;50 m $\times$ $0.32 \mathrm{~mm} \times 0.17 \mu \mathrm{m})$ and an automatic sampler (HP-7683), was run under the following conditions; injection volume, $1 \mu \mathrm{L}$; splitless injection temperature, $310^{\circ} \mathrm{C}$ and ion source temperature, $310^{\circ} \mathrm{C}$. The oven temperature increased from $50^{\circ} \mathrm{C}$ to $100^{\circ} \mathrm{C}$ at $20^{\circ} \mathrm{C}$ per min, and then from $100^{\circ} \mathrm{C}$ to $290^{\circ} \mathrm{C}$ at $3^{\circ} \mathrm{C}$ per min; the final temperature, $290^{\circ} \mathrm{C}$, was maintained for $40 \mathrm{~min}$. The limits of detection (LODs) for the 16 PAH compounds were $0.023-0.106 \mathrm{ng}$, and the recovery efficiencies were $83.9-92.6 \%$ (average $=86.4 \%$ ). Additional analysis parameters and procedures of GC/MSD can be found elsewhere (Lin et al., 2017).

The 16 PAHs compounds were divided into three categories based on their molecular weights as low molecular weight (LMW), medium molecular weight (MMW), and high molecular weight (HMW). The LMWPAHs were naphthalene (Nap), acenaphthylene (AcPy), acenaphthene (Acp), fluorine (Flu), phenanthrene (PA), and anthracene (Ant), while the MMW-PAHs were fluoranthene (FL), pyrene (Pyr), benzo[a]anthracene $(\mathrm{BaA})$, and chrysene (CHR). The HMW-PAHs were benzo[b]fluoranthene (BbF), benzo[k]fluoranthene $(\mathrm{BkF})$, benzo(a)pyrene $(\mathrm{BaP})$, dibenzo[a,h]anthracene (DBA), indeno[1,2,3,-cd]pyrene (IND), and benzo[ghi]perylene (Bghip). The carcinogenic factors of the identified PAHs were determined in terms of $\mathrm{BaP}_{\mathrm{eq}}$, from the toxic equivalence factors (TEFs) of these compounds (PAH concentration $\times$ TEF). This study utilized the TEFs were specified by Nisbet and LaGoy (1992). The carcinogenic potency of Total-PAHs (Total-BaP ${ }_{\text {eq }}$ ) was evaluated by summing the $\mathrm{BaP}_{\mathrm{eq}}$ concentrations of individual PAH compounds.

\section{RESULTS AND DISCUSSION}

\section{Emission Factors of $\mathrm{HC}, \mathrm{CO}$, and $\mathrm{NO}_{\boldsymbol{x}}$}

The tested fuels were first prepared by adding $4 \%$ of three 2-stroke engine oils (LS, MS, and SLS) to each respective sample of 92-gasoline. A P2SGE was operated at 3,800 rpm (idling), 5,000 rpm, 6,000 rpm, and 7,000 rpm to investigate the emission factors (EFs) based on the fuel consumption $\left(\mathrm{g} \mathrm{L}^{-1}\right.$ ) of $\mathrm{HC}, \mathrm{CO}$, and $\mathrm{NO}_{\mathrm{x}}$ by using various fuels (as displayed in Fig. 1). Experimental results show that the $\mathrm{HC}$ and $\mathrm{CO}$ EFs decreased with increasing engine speed, while $\mathrm{NO}_{\mathrm{x}}$ EFs exhibited the opposite trend. Generally, $\mathrm{HC}$ and $\mathrm{CO}$ are the products of incomplete combustion from hydrocarbon. $\mathrm{HC}$ was formed from the quenching zone near the cool inner wall of the cylinder during combustion. The lower temperature condition reinforced this phenomenon, but inhibited the $\mathrm{NO}_{\mathrm{x}}$ emission. The P2SGE exhaust temperatures were $40.9 \pm$ $0.67,52.3 \pm 0.95,72.6 \pm 2.89$, and $92.4 \pm 3.04^{\circ} \mathrm{C}$, when operated at 3,800 rpm, 5,000 rpm, 6,000 rpm, and 7,000 rpm, respectively. Thus, the idling condition had the lowest temperature, indicating the most incomplete combustion among the tests, and leading to higher EFs of $\mathrm{HC}$ and $\mathrm{CO}$ and lower EFs of $\mathrm{NO}_{\mathrm{x}}$. The data in Fig. 1 indicate that, at various speeds except for idling condition, the additions of 4\% LS 


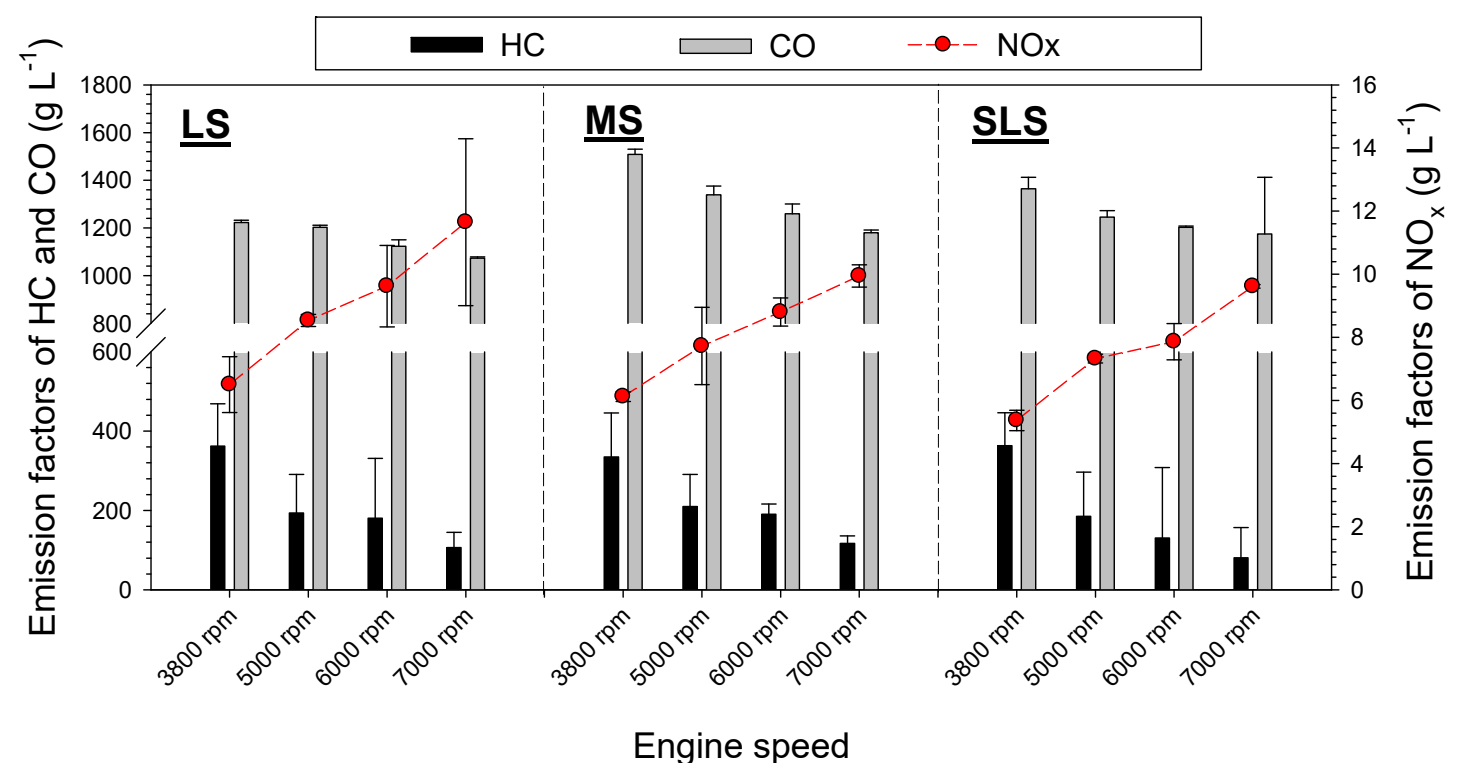

Fig. 1. Emission factors of $\mathrm{HC}, \mathrm{CO}$, and $\mathrm{NO}_{\mathrm{x}}$ from a P2SGE by using SLS, LS, and MS operated at various loads.

and SLS could reduce HC emissions by $16 \%$ (on average) compared with adding MS, while the average reduction rate of $\mathrm{CO}$ emissions was $8.8 \%$. Additionally, using SLS additive lowered $\mathrm{NO}_{\mathrm{x}}$ emissions by $7.9 \%$ (on average). The above phenomenon could result from the different physical and chemical properties of the 2-stroke engine oils used in gasoline.

\section{Performance of Engine Power and Fuel Consumption}

Table 2 presents the fuel consumption (FC) and specific fuel consumption (SFC) of P2SGE using 4 vol.\% of LS, MS, and SLS lubricants in 92-gasoline. In these tests, the LS additive showed the best power output, followed by SLS at 5,000 rpm, while the SLS additive provided the highest P2SGE output power at 7,000 rpm. Use of SLS and LS increased the engine power from using MS by $3.3 \%$ and $3.5 \%$, respectively. The three lubricants applied in the current study did not have significant effect on FC or SFC of P2SGE at the same speed, while the consumption of fuels (FC and SFC) all increased with an increase in engine speed. Additionally, the power output was $0 \mathrm{kWh}, 1.46-1.52 \mathrm{kWh}$, and 1.85 $1.91 \mathrm{kWh}$, while the P2SGE was operated at 3,800 rpm, $5,000 \mathrm{rpm}$, and 7,000 rpm, respectively. Therefore, the following discussion focuses on the variation of pollutant emissions at idling $(0 \mathrm{~kW})$, medium load $(\sim 1.5 \mathrm{~kW})$, and high load $(\sim 1.9 \mathrm{~kW})$.

\section{PM Concentrations and Emission Factors in the Exhaust}

The PM concentrations and emission factors (EFs) of PM in terms of unit fuel consumption $\left(\mathrm{EF}_{\mathrm{FC}}\right)$ and output energy $\left(\mathrm{EF}_{\text {energy }}\right)$ from the exhaust of P2SGE operated at idling $(0 \mathrm{~kW})$, medium load $(\sim 1.5 \mathrm{~kW})$, and high load $(\sim 1.9 \mathrm{~kW})$ when using 4 vol.\% of SLS, LS, or MS as the additive in 92gasoline are shown in Figs. 2 and 3. According to Fig. 2, the $\mathrm{PM}$ emission decreased with increasing engine load when using all lubricants, while the addition of 4 vol.\% LS led to the lowest PM emission concentration. Thus, the idling operation had the highest PM emission level, followed by mediumload $(5,000 \mathrm{rpm})$ and high-load conditions $(7,000 \mathrm{rpm})$. This result might be caused by the higher combustion temperature at high load $\left(92.4 \pm 3.04^{\circ} \mathrm{C}\right)$ than at medium load $(52.3 \pm$ $\left.0.95^{\circ} \mathrm{C}\right)$ and idling $\left(40.9 \pm 0.67^{\circ} \mathrm{C}\right)$ operation, which provided more complete combustion of fuels, thus reducing the formation of PM. Compared with $4 \% \mathrm{MS}$ additive, the LS addition could reduce the mass concentrations, $\mathrm{EF}_{\mathrm{FC}}$, and $\mathrm{EF}_{\text {energy }}$ of PM by $25.4-42.2 \%$ (average $35.1 \%$ ), 21.7-42.3\% (32.6\% in average), and $25.0-37.2 \%$ (31.1\% in average), respectively, under all tested loads (as shown in Fig. 3). This could resulted from MS having a significantly lower flash point $\left(136^{\circ} \mathrm{C}\right)$ than the others (Table 1$)$, since a higher flash point leads to lower vaporization ability at the early stage of combustion. The lower vaporization speed from using MS could led to less complete combustion, and caused higher PM emissions than using other lubricants.

Ålander et al. (2005) focused on the effects of particle emissions from a small two-stroke gasoline engine using various fuels, lubricants and catalytic converters. The untreated emission from the test engine fueled with alkylate fuelbiodegradable oil had a higher PM emission factor (3.42 \pm $\left.0.15 \mathrm{~g} \mathrm{kWh}^{-1}\right)$ and $19-50 \%$ lower PM $\left(1.72 \pm 0.11 \mathrm{~g} \mathrm{kWh}^{-1}\right)$ when adopting a catalytic converter. The average overall PM emission factor was $2.59 \mathrm{~g} \mathrm{kWh}^{-1}$, which was only about $1 \%$ of those found in the current study (35.9-57.2 $\mathrm{g} \mathrm{kWh}^{-1}$, avg. $43.3 \mathrm{~g} \mathrm{kWh}^{-1}$ ).

\section{Concentrations and Emission Factors of PM-bound Carbonaceous Species}

Table 3 lists the mass concentrations and emission factors of PM-bound carbonaceous species (TC, EC and OC) from the exhaust of P2SGE using 4 vol.\% of LS, MS, and SLS lubricants in 92-gasoline. Increasing P2SGE load reduced the TC and OC emission concentrations regardless of the lubricant used. The maximum EC concentration occurred at medium load, followed by the idling and high-load operations. 
Table 2. The performance of engine power, fuel consumption, and specific fuel consumption.

\begin{tabular}{|c|c|c|c|c|c|c|c|c|c|}
\hline \multirow{2}{*}{$\begin{array}{l}\text { Engine speed } \\
(\mathrm{rpm})\end{array}$} & \multicolumn{3}{|c|}{ Engine Power $(\mathrm{kWh})(\mathrm{N}=15)$} & \multicolumn{3}{|c|}{$\mathrm{FC}\left(\mathrm{L} \mathrm{hr}^{-1}\right)(\mathrm{N}=6)$} & \multicolumn{3}{|c|}{$\mathrm{SFC}\left(\mathrm{L} \mathrm{kWh}^{-1}\right)(\mathrm{N}=6)$} \\
\hline & SLS & LS & $\mathrm{MS}$ & SLS & LS & MS & SLS & LS & MS \\
\hline $\begin{array}{l}3800 \mathrm{rpm} \\
\text { (idling) }\end{array}$ & 0.00 & 0.00 & 0.00 & $\begin{array}{l}0.288 \\
( \pm 0.008)\end{array}$ & $\begin{array}{l}0.290 \\
( \pm 0.011)\end{array}$ & $\begin{array}{l}0.293 \\
( \pm 0.010)\end{array}$ & - & - & - \\
\hline $5000 \mathrm{rpm}$ & $\begin{array}{l}1.50 \\
( \pm 0.03)\end{array}$ & $\begin{array}{l}1.52 \\
( \pm 0.03)\end{array}$ & $\begin{array}{l}1.46 \\
( \pm 0.03)\end{array}$ & $\begin{array}{l}0.455 \\
( \pm 0.012)\end{array}$ & $\begin{array}{l}0.460 \\
( \pm 0.040)\end{array}$ & $\begin{array}{l}0.463 \\
( \pm 0.015)\end{array}$ & $\begin{array}{l}0.303 \\
( \pm 0.008)\end{array}$ & $\begin{array}{l}0.303 \\
( \pm 0.026)\end{array}$ & $\begin{array}{l}0.318 \\
( \pm 0.010)\end{array}$ \\
\hline $7000 \mathrm{rpm}$ & $\begin{array}{l}1.91 \\
( \pm 0.05)\end{array}$ & $\begin{array}{l}1.90 \\
(0.04)\end{array}$ & $\begin{array}{l}1.85 \\
( \pm 0.03)\end{array}$ & $\begin{array}{l}0.608 \\
( \pm 0.010)\end{array}$ & $\begin{array}{l}0.613 \\
( \pm 0.016)\end{array}$ & $\begin{array}{l}0.618 \\
( \pm 0.020)\end{array}$ & $\begin{array}{l}0.318 \\
( \pm 0.005)\end{array}$ & $\begin{array}{l}0.323 \\
( \pm 0.009)\end{array}$ & $\begin{array}{l}0.335 \\
( \pm 0.011)\end{array}$ \\
\hline
\end{tabular}

-: Unavailable.

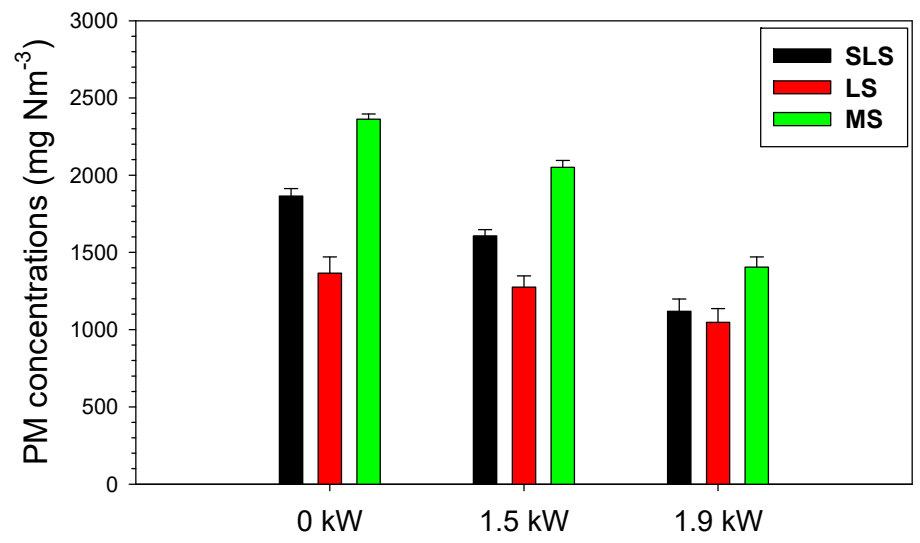

Fig. 2. Mass concentrations of PM emitted from a P2SGE by using SLS, LS, and MS operated at various loads.

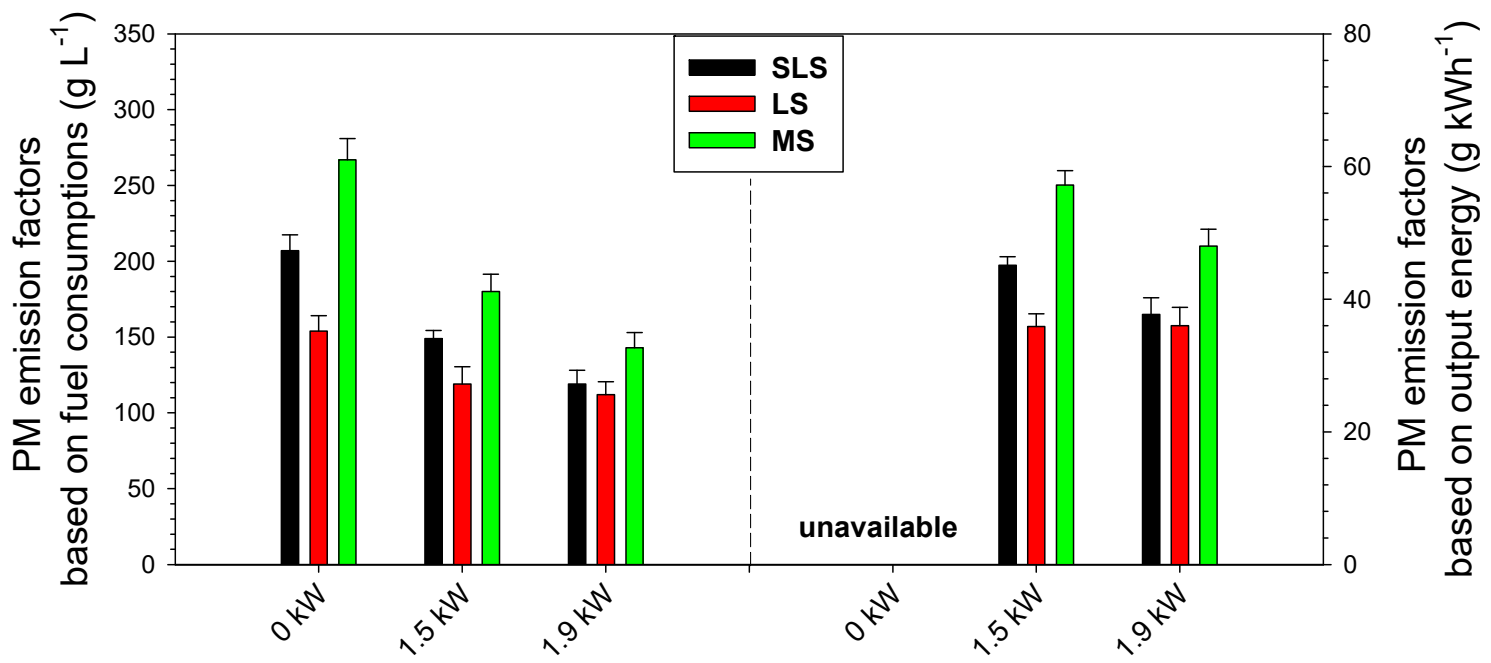

Fig. 3. Emission factors of PM from a P2SGE by using SLS, LS, and MS operated at various loads.

Among the tested lubricants, the LS had the lowest PMcarbonaceous species emissions, while the MS had the maximum emissions at all engine loads. The application of LS provided $13.1 \%, 14.7 \%$, and $17.1 \%$ lower emissions of TC, EC, and OC, respectively, than those of using SLS, except that of EC at high load. Conversely, the MS addition increased $32.8 \% \mathrm{TC}, 39.0 \% \mathrm{EC}$, and $24.7 \%$ OC emissions in comparison to the SLS addition. Additionally, OC was found to be higher concentrations than EC at idling condition of P2SGE, but an opposite trend was observed at the middle or high load. This finding was associated with the incompletely combusted hydrocarbons at idling operation of the two- stroke engine (with the lowest exhaust temperature). Moreover, the temperature of emission rose to $50-90^{\circ} \mathrm{C}$ at $1.5 \mathrm{~kW}$ and $1.9 \mathrm{~kW}$ loads, indicating more complete combustion in engine cylinder. Irrespective of the use of different 2-stroke oils, the EFs of OC in terms of unit fuel consumption $\left(\mathrm{EF}_{\mathrm{FC}}\right)$ and output energy ( $\left(\mathrm{EF}_{\text {energy }}\right)$ were lower than those of $\mathrm{EC}$ at medium and high loads, while the opposite trend (OC $>$ EC) was observed at idling operation. Additionally, emissions of carbonaceous $\mathrm{EF}_{\mathrm{FC}}$ and $\mathrm{EF}_{\text {energy }}$ were lowest when utilizing the LS additive, followed by the SLS and MS, at all three engine loads. Compared to SLS additive, the EFFC reductions of TC, $\mathrm{EC}$, and $\mathrm{OC}$ for using 4 vol.\% LS additive under the three 
Table 3. Mass concentrations and emission factors of particle-bound TC, EC, and OC.

\begin{tabular}{|c|c|c|c|c|c|c|c|c|c|}
\hline & \multicolumn{3}{|c|}{ SLS } & \multicolumn{3}{|c|}{$\mathrm{LS}$} & \multicolumn{3}{|c|}{ MS } \\
\hline & $\mathrm{TC}$ & $\mathrm{EC}$ & $\mathrm{OC}$ & $\mathrm{TC}$ & $\mathrm{EC}$ & $\mathrm{OC}$ & $\mathrm{TC}$ & $\mathrm{EC}$ & $\mathrm{OC}$ \\
\hline \multicolumn{10}{|c|}{ Mass concentrations $\left(\mathrm{mg} \mathrm{Nm}^{-3}\right)(\mathrm{N}=3)$} \\
\hline $0 \mathrm{~kW}$ (idling) & $\begin{array}{l}1566 \\
( \pm 46.3)\end{array}$ & $\begin{array}{l}655 \\
( \pm 42.5)\end{array}$ & $\begin{array}{l}912 \\
( \pm 57.0)\end{array}$ & $\begin{array}{l}1235 \\
( \pm 66.7)\end{array}$ & $\begin{array}{l}547 \\
( \pm 92.1)\end{array}$ & $\begin{array}{l}689 \\
( \pm 25.8)\end{array}$ & $\begin{array}{l}2090 \\
( \pm 33.5)\end{array}$ & $\begin{array}{l}867 \\
( \pm 31.0)\end{array}$ & $\begin{array}{l}1223 \\
( \pm 23.4)\end{array}$ \\
\hline $\begin{array}{l}1.5 \mathrm{~kW} \\
\text { (medium load) }\end{array}$ & $\begin{array}{l}1333 \\
( \pm 60.4)\end{array}$ & $\begin{array}{l}726 \\
( \pm 32.1)\end{array}$ & $\begin{array}{l}608 \\
( \pm 36.3)\end{array}$ & $\begin{array}{l}1110 \\
( \pm 61.3)\end{array}$ & $\begin{array}{l}633 \\
( \pm 16.5)\end{array}$ & $\begin{array}{l}477 \\
( \pm 55.8)\end{array}$ & $\begin{array}{l}1753 \\
( \pm 38.1)\end{array}$ & $\begin{array}{l}1031 \\
( \pm 57.9)\end{array}$ & $\begin{array}{l}723 \\
( \pm 91.7)\end{array}$ \\
\hline $\begin{array}{l}1.9 \mathrm{~kW} \\
\text { (high load) }\end{array}$ & $\begin{array}{l}913 \\
( \pm 74.0)\end{array}$ & $\begin{array}{l}526 \\
( \pm 23.0)\end{array}$ & $\begin{array}{l}386 \\
( \pm 49.6)\end{array}$ & $\begin{array}{l}901 \\
( \pm 62.7)\end{array}$ & $\begin{array}{l}535 \\
( \pm 44.8)\end{array}$ & $\begin{array}{l}366 \\
( \pm 23.1)\end{array}$ & $\begin{array}{l}1217 \\
( \pm 52.4)\end{array}$ & $\begin{array}{l}750 \\
( \pm 25.2)\end{array}$ & $\begin{array}{l}467 \\
( \pm 55.6)\end{array}$ \\
\hline \multicolumn{10}{|l|}{ Emission factors } \\
\hline \multicolumn{10}{|c|}{ 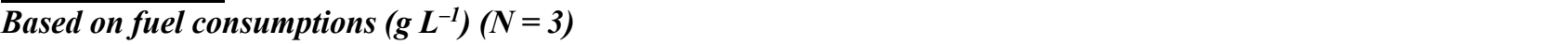 } \\
\hline $0 \mathrm{k}$ & $\begin{array}{l}0.171 \\
( \pm 0.01\end{array}$ & $\begin{array}{l}0.071 \\
( \pm 0.002)\end{array}$ & $\begin{array}{l}0.100 \\
( \pm 0.011)\end{array}$ & $\begin{array}{l}0.138 \\
( \pm 0.005)\end{array}$ & $\begin{array}{l}0.061 \\
( \pm 0.009)\end{array}$ & $\begin{array}{l}0.077 \\
( \pm 0.005)\end{array}$ & $\begin{array}{l}0.242 \\
( \pm 0.006)\end{array}$ & $\begin{array}{l}0.101 \\
( \pm 0.002)\end{array}$ & $\begin{array}{l}0.142 \\
( \pm 0.006)\end{array}$ \\
\hline $\begin{array}{l}1.5 \mathrm{~kW} \\
\text { (medium load) }\end{array}$ & $\begin{array}{l}0.125 \\
( \pm 0.008)\end{array}$ & $\begin{array}{l}0.068 \\
( \pm 0.004)\end{array}$ & $\begin{array}{l}0.057 \\
( \pm 0.004)\end{array}$ & $\begin{array}{l}0.106 \\
( \pm 0.004)\end{array}$ & $\begin{array}{l}0.060 \\
( \pm 0.003)\end{array}$ & $\begin{array}{l}0.045 \\
( \pm 0.004)\end{array}$ & $\begin{array}{l}0.146 \\
( \pm 0.004)\end{array}$ & $\begin{array}{l}0.086 \\
( \pm 0.004)\end{array}$ & $\begin{array}{l}0.060 \\
( \pm 0.008)\end{array}$ \\
\hline $\begin{array}{l}1.9 \mathrm{~kW} \\
\text { (high load) }\end{array}$ & $\begin{array}{l}0.097 \\
( \pm 0.008)\end{array}$ & $\begin{array}{l}0.056 \\
( \pm 0.003)\end{array}$ & $\begin{array}{l}0.041 \\
( \pm 0.005)\end{array}$ & $\begin{array}{l}0.094 \\
( \pm 0.009)\end{array}$ & $\begin{array}{l}0.056 \\
( \pm 0.006)\end{array}$ & $\begin{array}{l}0.038 \\
( \pm 0.003)\end{array}$ & $\begin{array}{l}0.121 \\
( \pm 0.006)\end{array}$ & $\begin{array}{l}0.074 \\
( \pm 0.002)\end{array}$ & $\begin{array}{l}0.046 \\
( \pm 0.006)\end{array}$ \\
\hline \multicolumn{10}{|c|}{ Based on output energy $\left(g k W h^{-1}\right)(N=3)$} \\
\hline 0 kW (idling) & - & - & - & - & - & - & - & - & - \\
\hline $\begin{array}{l}1.5 \mathrm{~kW} \\
\text { (medium load) }\end{array}$ & $\begin{array}{l}37.2 \\
( \pm 1.37)\end{array}$ & $\begin{array}{l}20.3 \\
( \pm 0.90)\end{array}$ & $\begin{array}{l}17.0 \\
( \pm 0.76)\end{array}$ & $\begin{array}{l}31.2 \\
( \pm 1.60)\end{array}$ & $\begin{array}{l}17.8 \\
( \pm 0.44)\end{array}$ & $\begin{array}{l}13.4 \\
( \pm 1.52)\end{array}$ & $\begin{array}{l}47.4 \\
( \pm 0.92)\end{array}$ & $\begin{array}{l}27.9 \\
( \pm 2.06)\end{array}$ & $\begin{array}{l}19.5 \\
( \pm 2.22)\end{array}$ \\
\hline $\begin{array}{l}1.9 \mathrm{~kW} \\
\text { (high load) }\end{array}$ & $\begin{array}{l}30.7 \\
( \pm 2.88)\end{array}$ & $\begin{array}{l}17.7 \\
( \pm 1.19)\end{array}$ & $\begin{array}{l}13.0 \\
( \pm 1.79)\end{array}$ & $\begin{array}{l}30.7 \\
( \pm 2.04)\end{array}$ & $\begin{array}{l}18.2 \\
( \pm 1.49)\end{array}$ & $\begin{array}{l}12.5 \\
( \pm 0.74)\end{array}$ & $\begin{array}{l}40.8 \\
( \pm 1.59)\end{array}$ & $\begin{array}{l}25.1 \\
( \pm 0.94)\end{array}$ & $\begin{array}{l}15.6 \\
( \pm 1.77)\end{array}$ \\
\hline
\end{tabular}

-: Unavailable.

engine loads were $12.6 \%, 12.8 \%$, and $16.7 \%$, respectively, while the $\mathrm{EF}_{\text {energy }}$ reduction values were $8.2 \%, 12.3 \%$, and $12.7 \%$, respectively. In contrast, the use of MS raised the EFs ( $\mathrm{EF}_{\mathrm{FC}}$ and $\left.\mathrm{EF}_{\text {energy }}\right)$ of TC, $\mathrm{EC}$, and $\mathrm{OC}$ by $16.7-42.0 \%$, $25.6-41.8 \%$, and 5.6-42.6\%, respectively, in comparison with using the SLS additive.

The order of average carbonaceous species contents on PM emitted from the P2SGE using different lubricating oils (as demonstrated in Fig. 4) were: MS (86.7\%) > SLS $(83.7 \%)>\operatorname{LS}(83.5 \%)$ for PM-bound TC; MS (46.7\%) > LS $(44.7 \%)>$ SLS (42.9\%) for PM-bound EC; and SLS (40.8\%) $>$ MS $(40.0 \%)>\operatorname{LS}(38.9 \%)$ for PM-bound OC. The PM mass contribution from $\mathrm{EC}$ and $\mathrm{OC}$ (or $\mathrm{TC}=\mathrm{EC}+\mathrm{OC}$ ) was $85 \%$, which declined with rising engine operation loads; this finding could strongly affect the combustion temperature and efficiency as stated in previous discussion. Similarly, some researchers have reported that particulate carbonaceous matters account for roughly one or two of third of PM mass in gasoline vehicle exhausts (Hao et al., 2019; Yang et al., 2019).

Zielinska et al. (2004) concluded that about $60 \%$ of PMbound $\mathrm{TC}$ were provided from $\mathrm{OC}$ mass $(\mathrm{EC} / \mathrm{TC}=0.4)$. Ålander et al. (2005) found that PM-bound TC contributed about $80 \%$ of mass of PM in the exhaust of a two-stroke gasoline engine (chainsaw), while PM-bound TC comprised almost entirely $\mathrm{OC}$ (EC/TC comprised only 1-6\%). Our finding that $\mathrm{EC}$ and $\mathrm{OC}$ contributed about $85 \%$ of PM weight is very similar to the aforementioned results. However, our finding that the PM-bound EC emissions increased with rising engine loads was different from those found in the references. The EC was emitted from the pyrolysis of oil droplets, while the $\mathrm{OC}$ content was mainly formed by the unburned fuel oil and lubricants (Abdul-Khalek et al., 1998). Additionally, EC and OC emission could be also affected by factors such as engine type, fuel property, and combustion control.

\section{PAH Mass and BaP $P_{\text {eq }}$ Concentrations and Emission Factors in the Exhaust}

The $\Sigma$ PAHs (total concentrations of 16 PAHs) or $\Sigma \mathrm{BaP}_{\mathrm{eq}}$ concentrations showed a minimum value by using LS, followed by using SLS and MS at medium and high loads (Fig. 5). The use of SLS and LS reduced PAH concentrations by 46.4 and $59.7 \%$, respectively, in comparison to using MS. The $\mathrm{BaP}_{\text {eq }}$ concentration was reduced by 54.8 and $49.2 \%$, respectively. The LMW-PAHs, MMW-PAHs, HMW-PAHs, $\Sigma \mathrm{PAHs}$, and $\Sigma \mathrm{BaP}_{\text {eq }}$ concentrations fell with increasing engine load, possibly owing to the higher combustion efficiency and destruction of aromatic structures at higher temperatures. Moreover, LMW-PAHs contributed 51.3-80.7\% (71.2\% on average) of $\Sigma$ PAHs concentrations, when MMW-PAHs was secondarily dominated (11.5-29.2\%, avg. 17.1\%) and followed by HMW-PAHs (6.41-19.5\%, avg. $11.7 \%)$ by using all kind of lubricants (as shown in Fig. 6). In contrast, the $\Sigma \mathrm{BaP}_{\text {eq }}$ concentration was predominated by HMW-PAHs (83.991.9\%, avg. 86.7\%), followed by MMW-PAHs (6.18$13.1 \%$, avg. 10.5\%) and LMW-PAHs (1.46-4.36\%, avg. $2.78 \%$ ). Additionally, Nap and PA dominated the PAH mass concentration $(40.0 \%$ and $14.0 \%)$ among 16 investigated homologs, while $\mathrm{BaP}$ and $\mathrm{BaA}$ mainly contributed the $\mathrm{BaP}_{\text {eq }}$ concentrations (69.4\% and $10.9 \%$, respectively), except using LS at high-load operation. Yang et al. (2005) reported that the $\mathrm{BaP}, \mathrm{IND}$, and DBA were the major components which accounted for $68.9 \%, 10.9 \%$, and $6.10 \%$ of PM-bound 


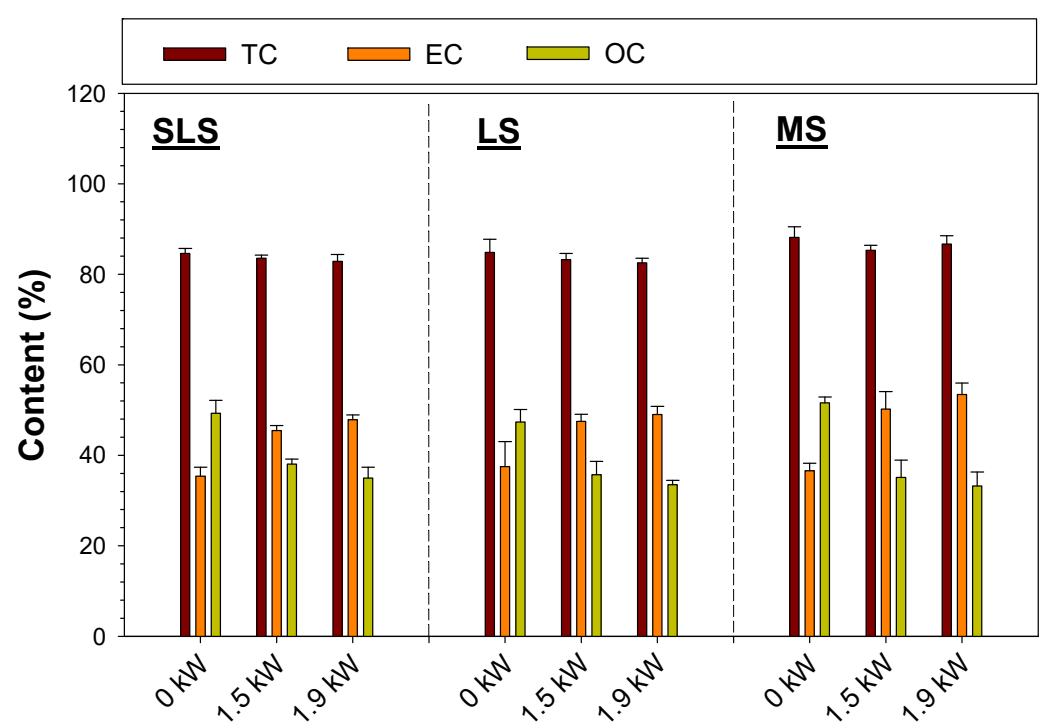

Fig. 4. Contents of TC, EC, and OC on PM emitted from a P2SGE by using SLS, LS, and MS operated at various loads.

total- $\mathrm{BaP}_{\mathrm{eq}}$ concentrations, respectively, in the exhaust of a two-stroke motorcycle.

Figs. 7 and 8 illustrate the PAH mass and toxicity emission factors based on the fuel consumption $\left(\mathrm{EF}_{\text {mass } / \mathrm{FC}}\right.$ and $\left.\mathrm{EF}_{\text {toxicity/ } / \mathrm{FC}}\right)$ and output energy $\left(\mathrm{EF}_{\text {mass/energy }}\right.$ and $\left.\mathrm{EF}_{\text {toxicity/energy }}\right)$ from the $\mathrm{P} 2 \mathrm{SGE}$ in this study. The $\mathrm{EF}_{\text {mass/FC }}, \mathrm{EF}_{\text {toxicity/FC, }} \mathrm{EF}_{\text {mass/energy, }}$ and $\mathrm{EF}_{\text {toxicity/energy }}$ (except $\Sigma$ PAHs $\mathrm{EF}_{\text {mass/energy }}$ using LS) of HMW-PAHs and $\Sigma$ PAHs decreased when the engine load rose with all the 2-stroke engine oil additives. The $\mathrm{EF}_{\text {mass/FC, }}$ $\mathrm{EF}_{\text {toxicity/FC, }} \mathrm{EF}_{\text {mass/energy, and }} \mathrm{EF}_{\text {toxicity/energy }}$ of $\Sigma \mathrm{PAHs}$ for using the lubricants were in the order MS $>$ SLS $>$ LS (except $\mathrm{EF}_{\text {toxicity/FC }}$ at idling operation). Compared to MS, the reductions of $\mathrm{EF}_{\text {mass/FC, }}, \mathrm{EF}_{\text {toxicity/FC, }} \mathrm{EF}_{\text {mass/energy, and }}$ $\mathrm{EF}_{\text {toxicity/energy }}$ of $\Sigma \mathrm{PAHs}$ by using SLS were $9.5 \%, 57.1 \%$, $87.6 \%$, and $90.0 \%$, respectively, while the corresponding data were $61.6 \%, 51.3 \%, 92.1 \%$, and $91.8 \%$, respectively, for using LS. As we know, the formation mechanisms of PAH during the engine operation comprise: (1) the PAH contents in fuels and lubricating oil; (2) the pyrosynthesis of from unburn hydrocarbon radicals; (3) the cyclization reaction from low-ring to high-ring PAHs or the thermal breakdown from high-ring to low-ring PAHs (Buñuel et al., 2006), and (4) the residual PAHs in the sampling system (Hall et al., 1998). In this work, the LS had the lowest PAH emissions among the three 2-stroke engine oils, which is possibly associated with their different aromatic content.

\section{CONCLUSIONS}

This study focuses on the use of different 2-stroke engine oil additives in a P2SGE with operation loads of idling $(0 \mathrm{~kW})$, medium-load $(1.5 \mathrm{~kW})$, and high-load (3.0 kW). The energy performance, traditional gaseous pollutants, PM, particle-bound carbons, and PAHs in the exhausts were explored. From this framework, the following conclusions can be derived.

- The emission factors of HC and CO decreased with increasing P2SGE load in spite of using different kinds of lubricants added into a two-stroke gasoline engine, but those of $\mathrm{NO}_{\mathrm{x}}$ exhibited the opposite trend. The LS and SLS additives reduced HC CO emissions by $16 \%$ and $8.8 \%$, respectively, in comparison to the addition of MS in 92-gasoline at all engine speeds. Using LS increased $\mathrm{NO}_{\mathrm{x}}$ by $10.8 \%$ when compared to those of using MS at all engine speeds, while adding SLS into 92-gasoline reduced $\mathrm{NO}_{\mathrm{x}}$ emission by $7.9 \%$.

- Both BSFC and FC increased with an increase in engine speed, but the addition of each tested lubricant did not significantly influence the FC or BSFC of P2SGE at the same speed. The mass concentrations and emission factors of PM followed the order MS > SLS > LS at all loads. The use of MS raised the PMbound TC, EC, and OC by $32.8 \%, 39.0 \%$, and $24.7 \%$, respectively, in comparison to using SLS.

- Carbonaceous matters (EC and OC) contributed 85\% of the PM mass emitted from the P2SGE in all test conditions. The emission factors based on the $\mathrm{FC}$ and output energy were higher for PM-bound OC than for $\mathrm{EC}$ at idling condition, while this trend was opposite $(\mathrm{OC}<\mathrm{EC})$ at medium $(1.5 \mathrm{~kW})$ and high $(1.9 \mathrm{~kW})$ engine loads. Additionally, the value of OC and EC decreased with increasing engine operation loads irrespective of the difference in 2-stroke engine oil composition.

- Nap and PA dominated the PAH mass concentration (40.0\% and $14.0 \%$, respectively) among 16 investigated homologs, while $\mathrm{BaP}$ and $\mathrm{BaA}$ mainly contributed the $\mathrm{BaP}_{\text {eq }}$ concentrations (69.4\% and $10.9 \%$, respectively), except using LS at high-load operation. Compared to using $\mathrm{MS}$, the reductions of $\Sigma \mathrm{PAHs}$ and $\Sigma \mathrm{BaP}_{\text {eq }}$ concentrations by using SLS were $46.4 \%$ and $54.8 \%$, respectively, while the reductions by using LS were $59.7 \%$ and $49.2 \%$, respectively.

- Overall, the LS additive generated the lowest PM, PM-bound carbons, $\Sigma \mathrm{PAHs}$, and $\Sigma \mathrm{BaP}_{\text {eq }}$ emissions at almost all test conditions. 
(A) idling (0 kW)

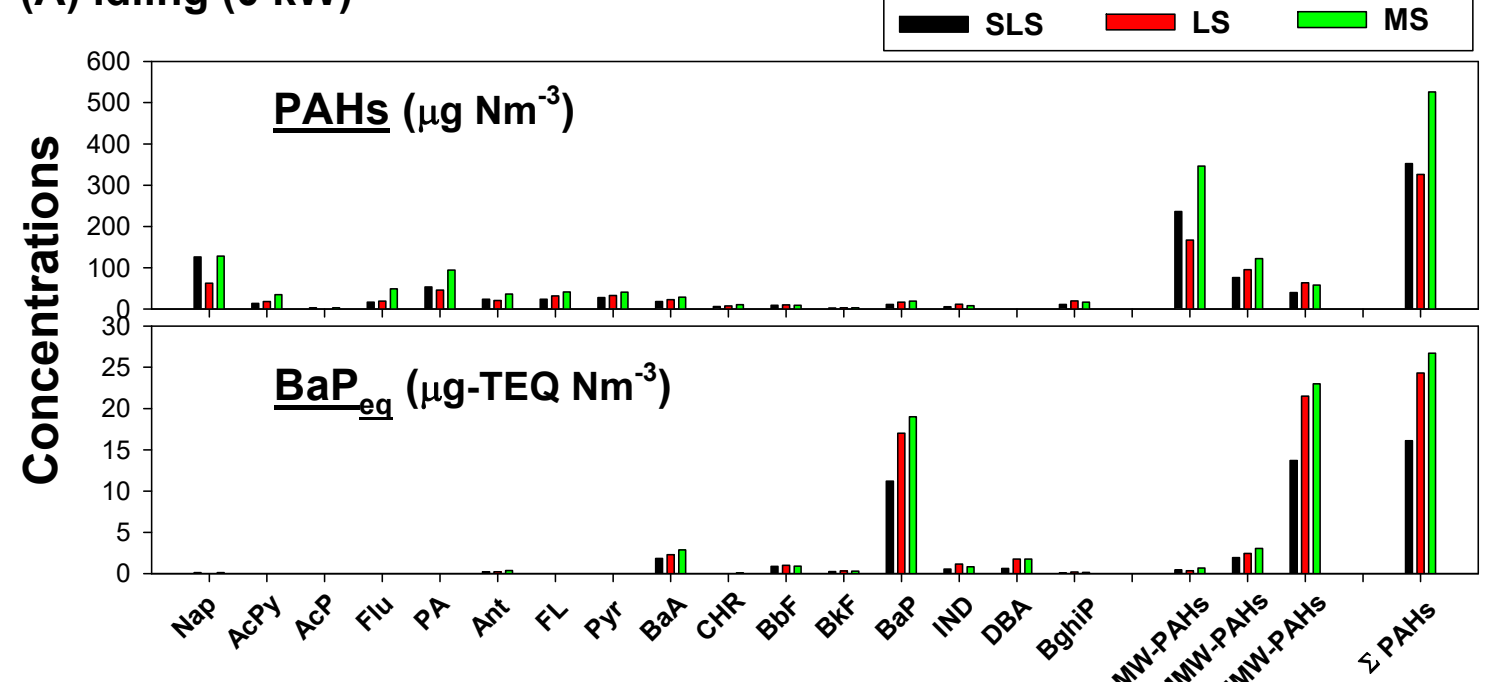

(B) medium-load (1.5 kW)

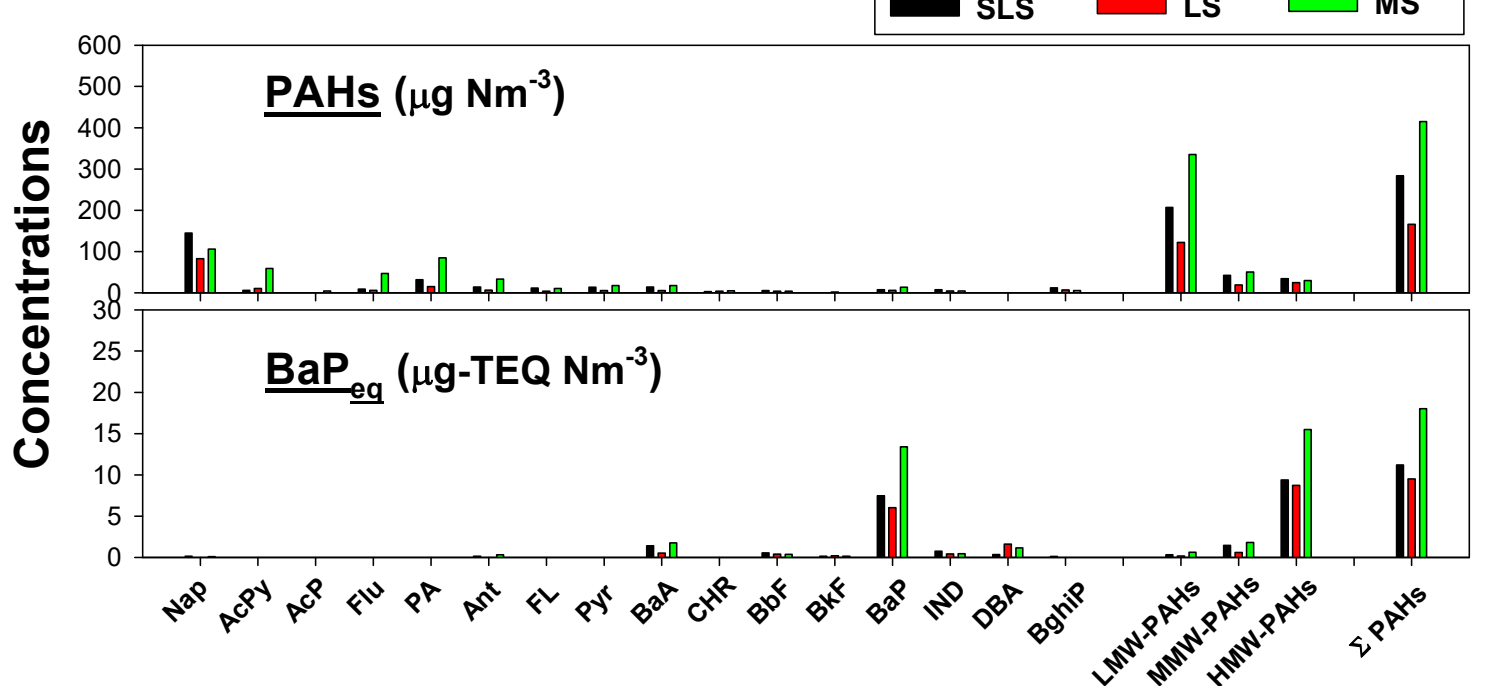

(C) high-load (3.0 kW)

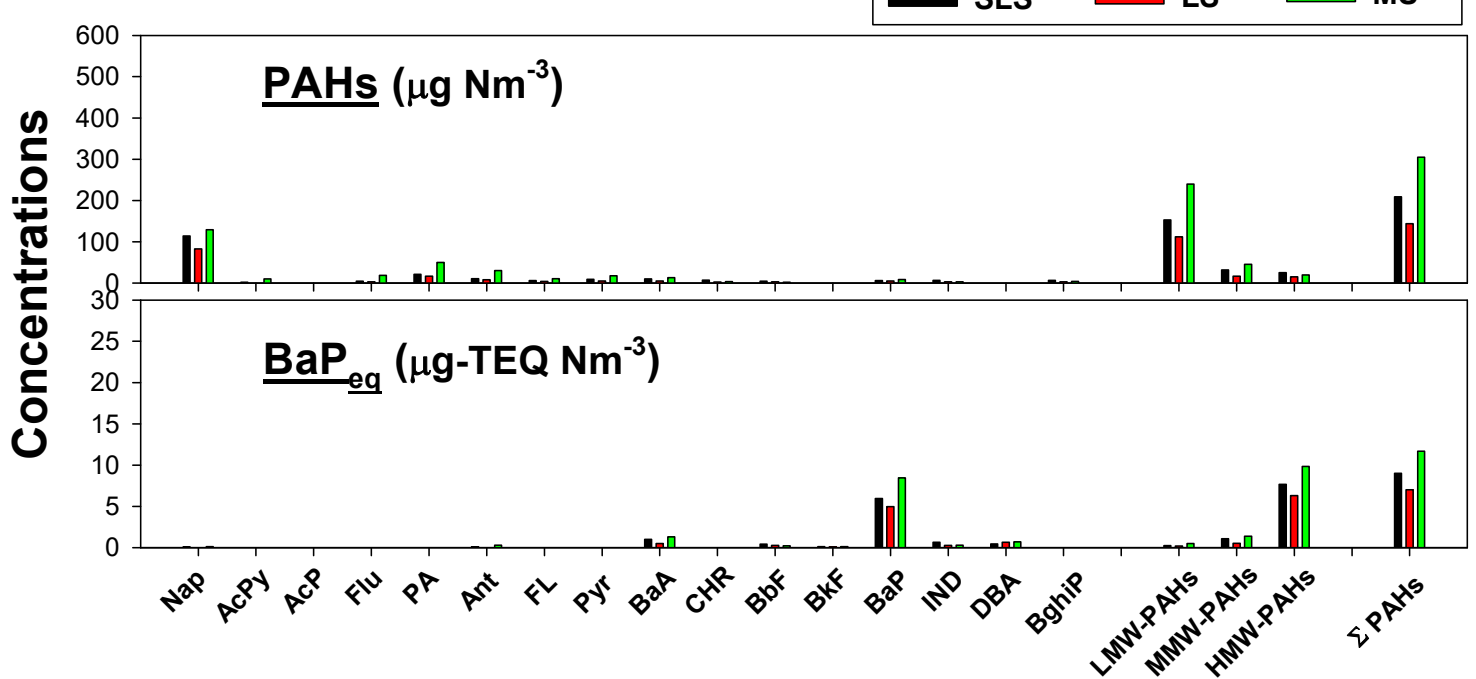

Fig. 5. Concentrations of $\mathrm{PAH}$ and $\mathrm{BaP}_{\text {eq }}$ congeners emitted from a P2SGE by using SLS, LS, and MS operated at (A) idling $(0 \mathrm{~kW}),(\mathrm{B})$ medium-load $(1.5 \mathrm{~kW})$, and (C) high-load $(3.0 \mathrm{~kW})$. 
(A) idling (0 kW)
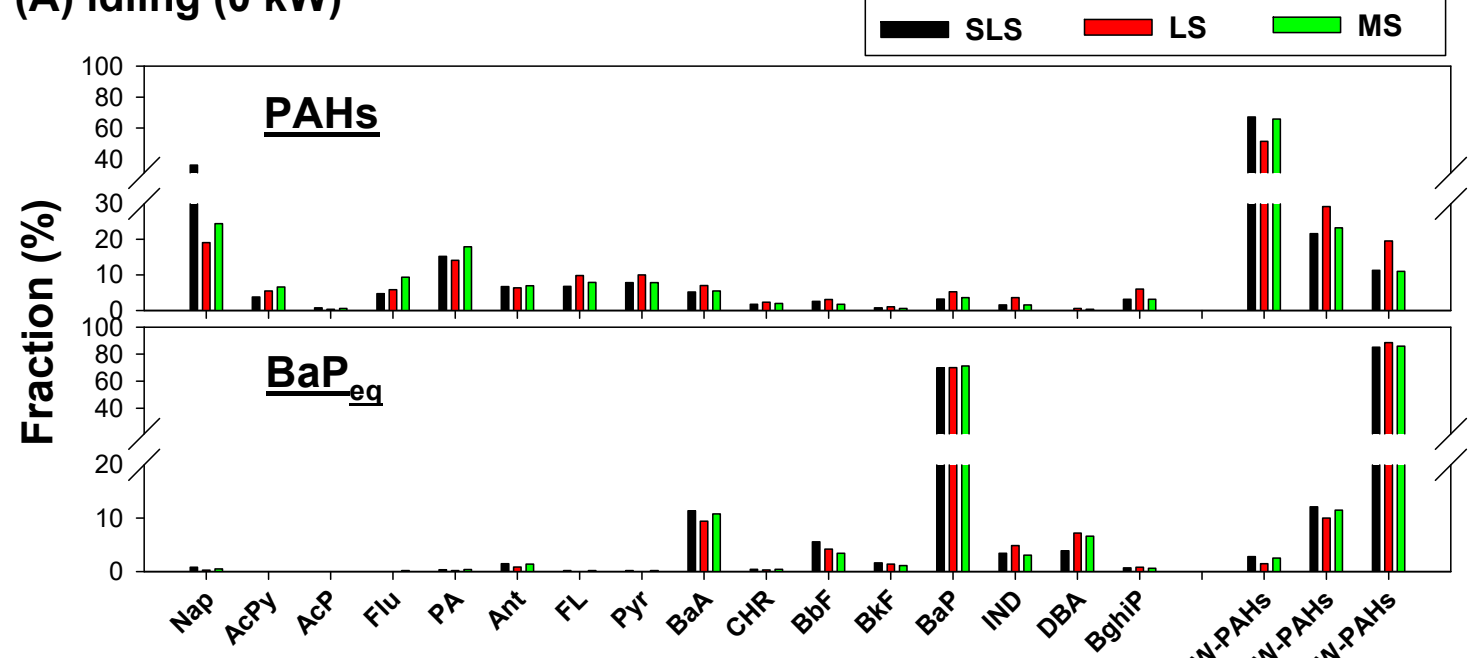

(B) medium-load (1.5 kW)

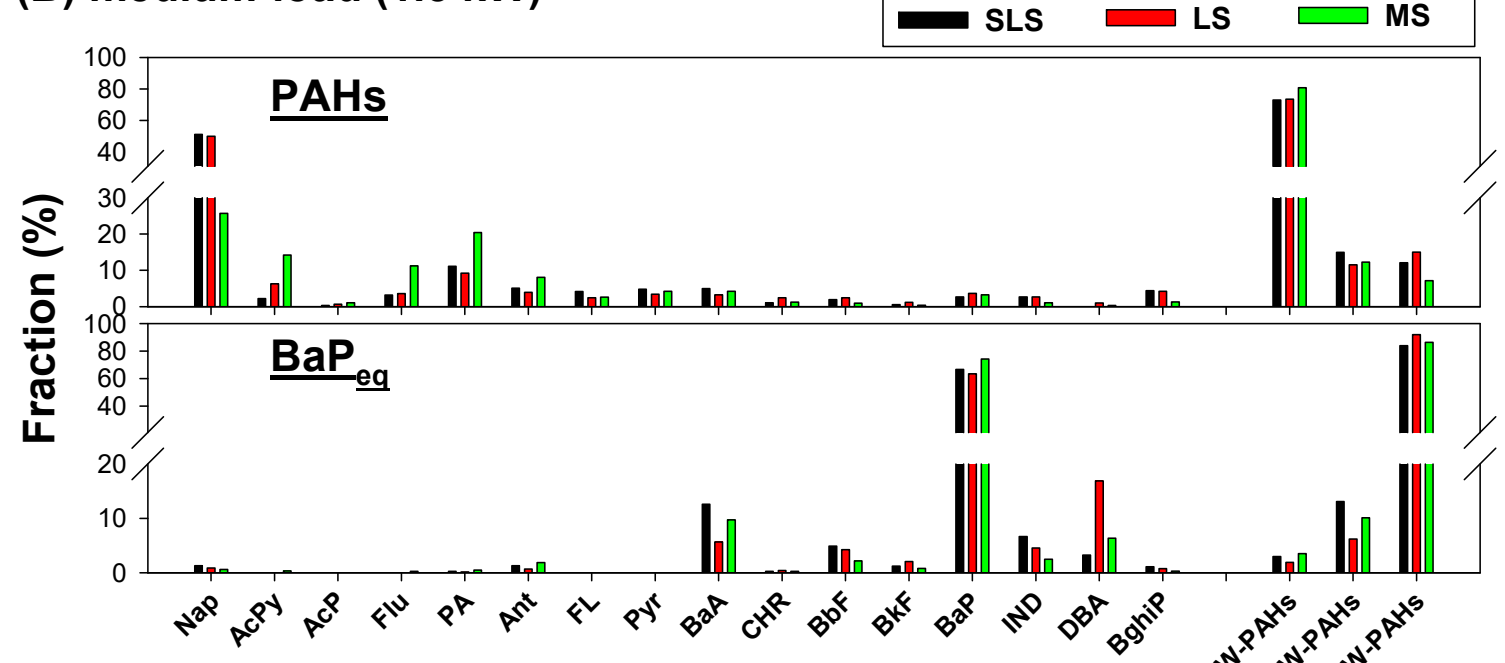

(C) high-load (3.0 kW)

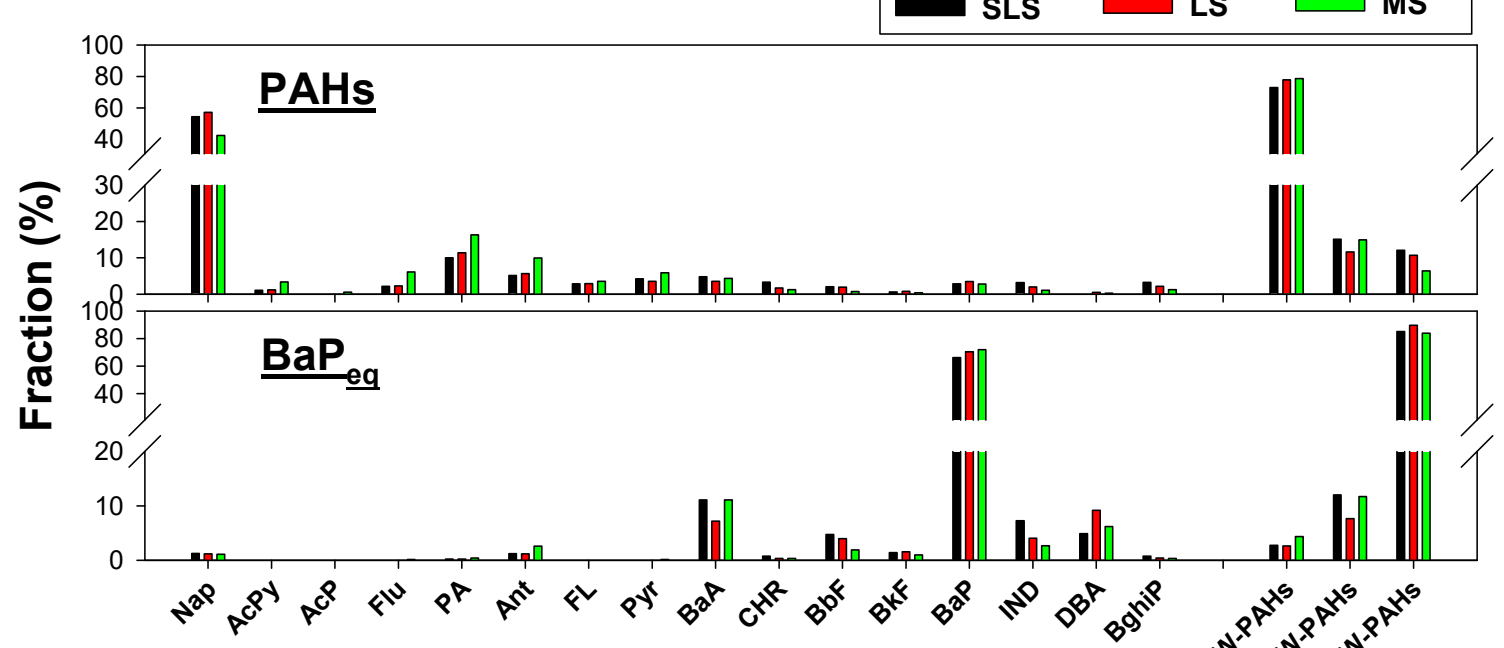

Fig. 6. Fractions of $\mathrm{PAH}$ and $\mathrm{BaP}_{\text {eq }}$ congeners emitted from a P2SGE by using SLS, LS, and MS operated at (A) idling $(0 \mathrm{~kW}),(\mathrm{B})$ medium-load $(1.5 \mathrm{~kW})$, and $(\mathrm{C})$ high-load $(3.0 \mathrm{~kW})$. 
(A) idling (0 kW)

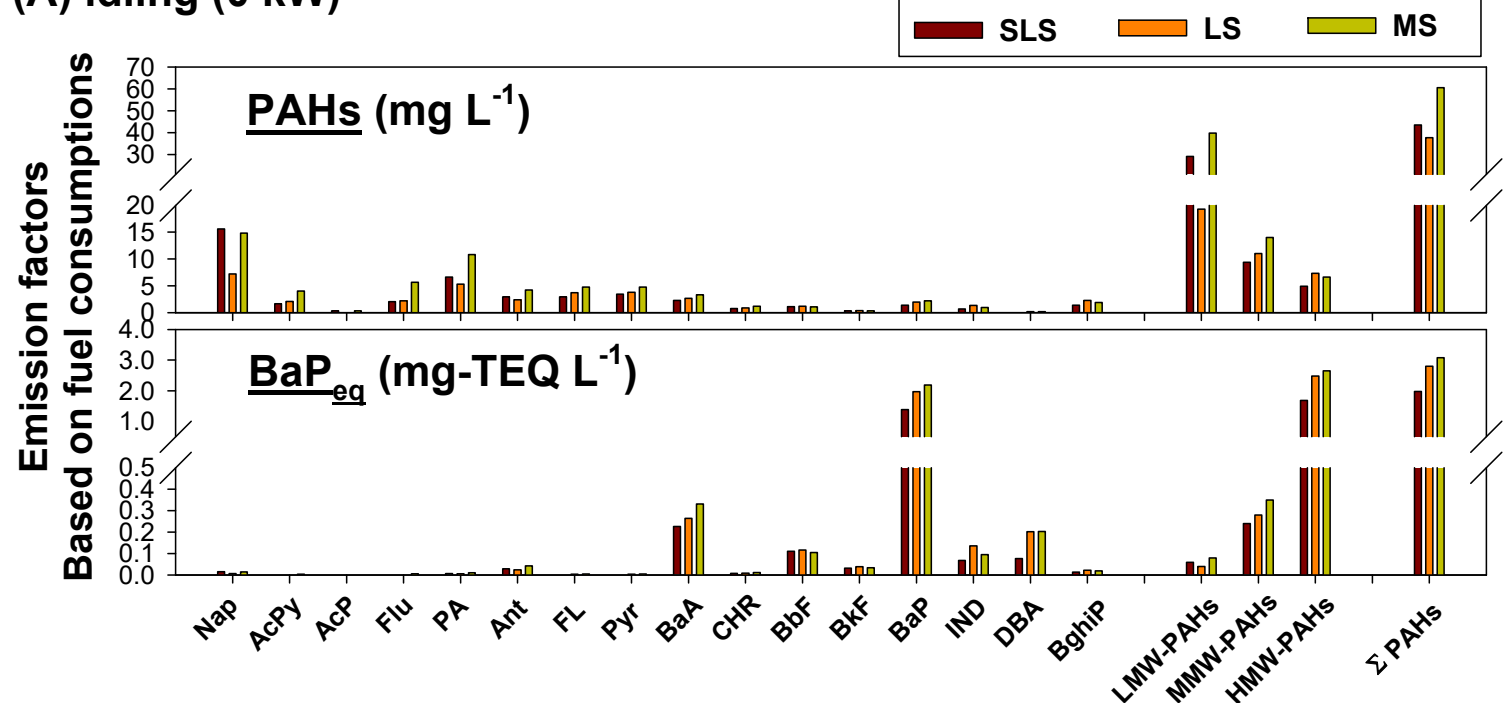

(B) medium-load (1.5 kW)

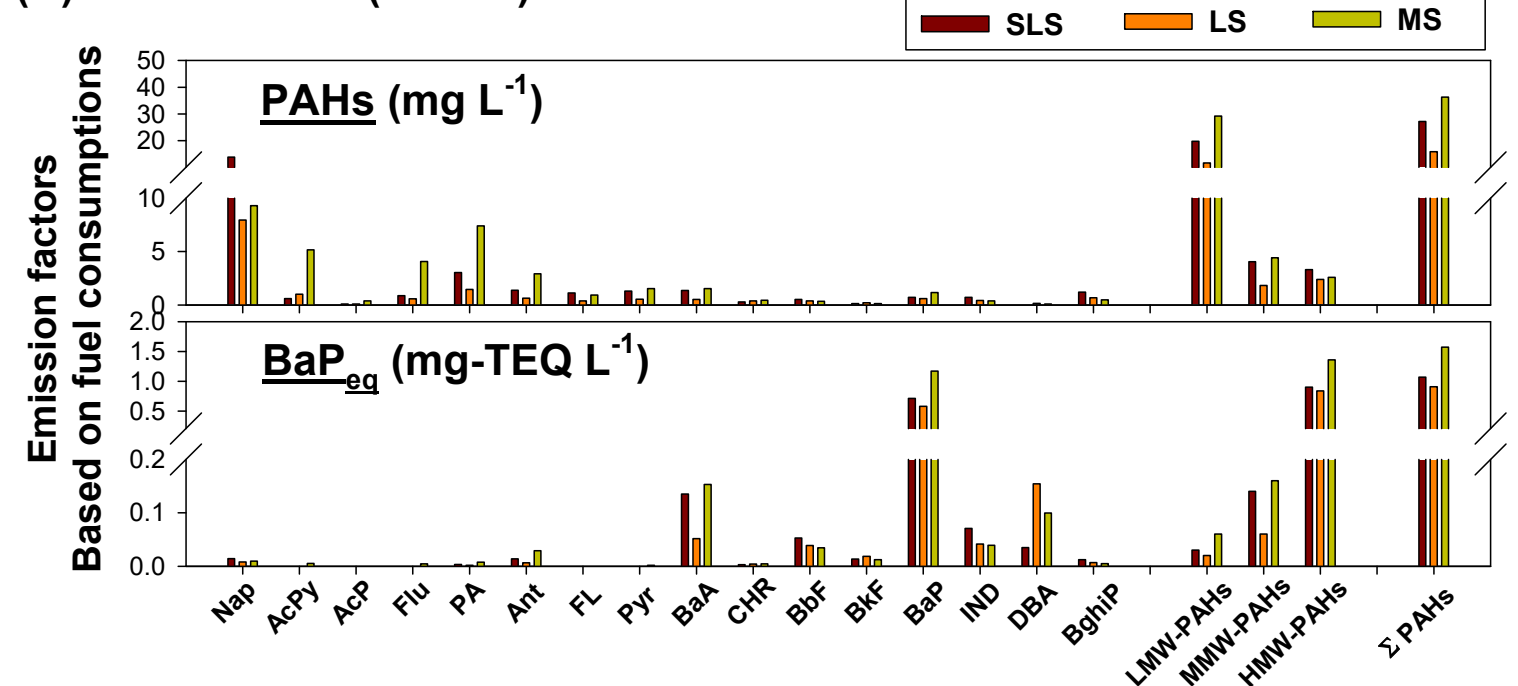

(C) high-load (3.0 kW)

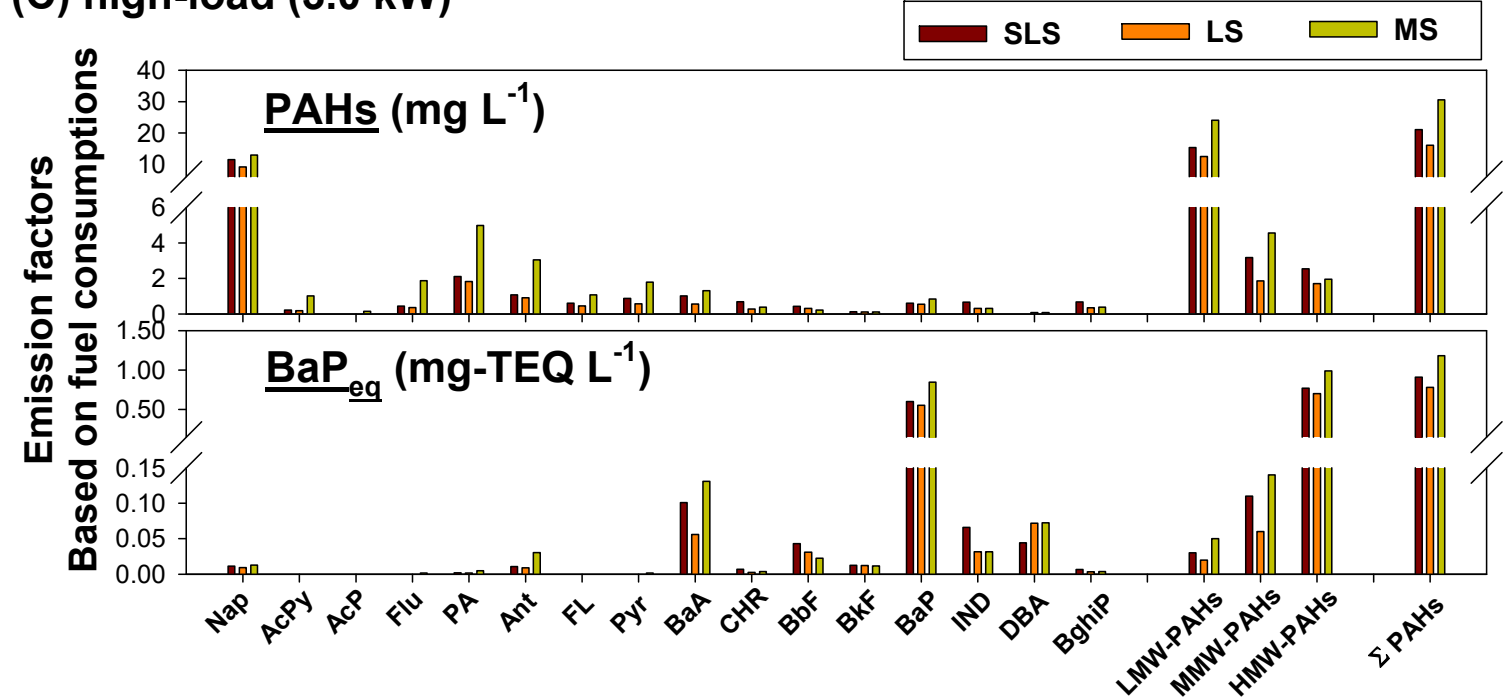

Fig. 7. Emission factors of $\mathrm{PAH}$ and $\mathrm{BaP}_{\text {eq }}$ congeners based on fuel consumptions emitted from a P2SGE by using SLS, LS, and MS operated at (A) idling (0 kW), (B) medium-load $(1.5 \mathrm{~kW})$, and (C) high-load (3.0 kW). 
(A) idling (0 kW)
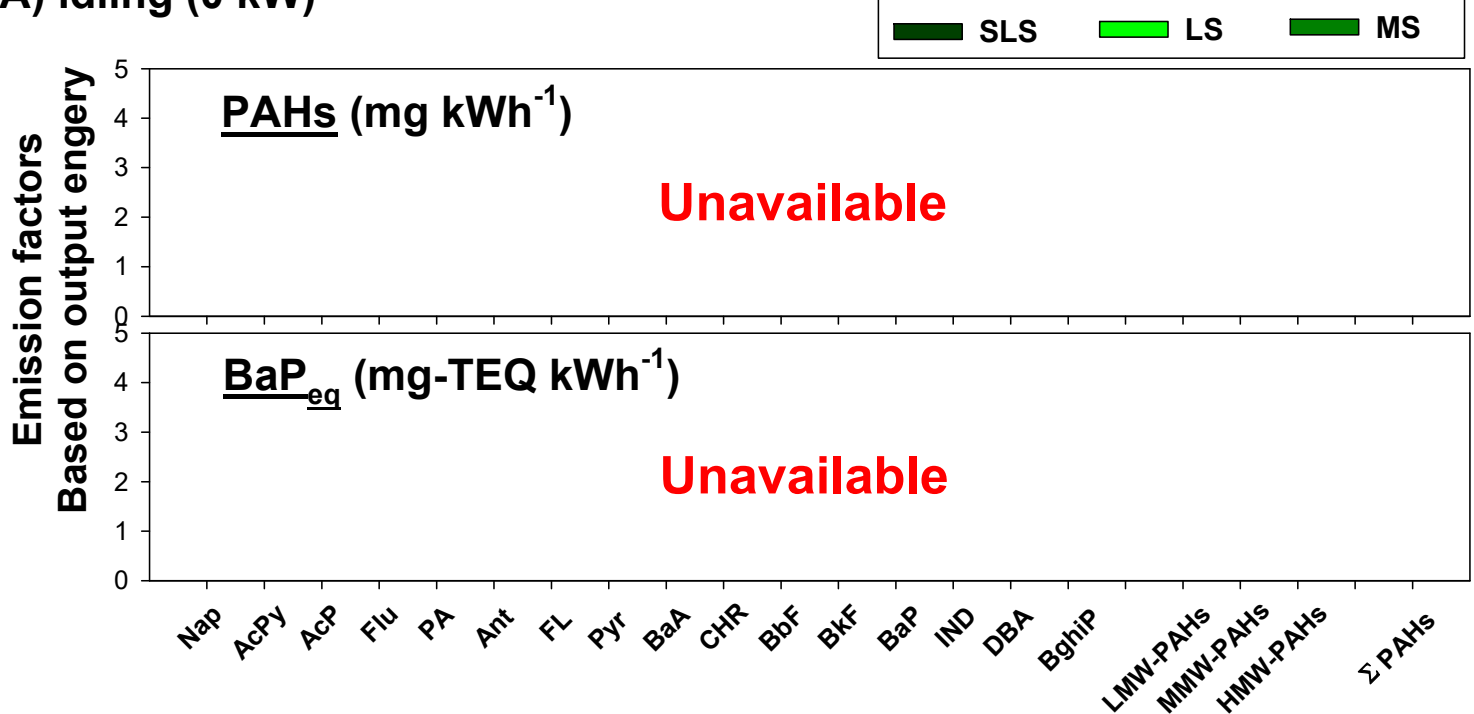

(B) medium-load (1.5 kW)

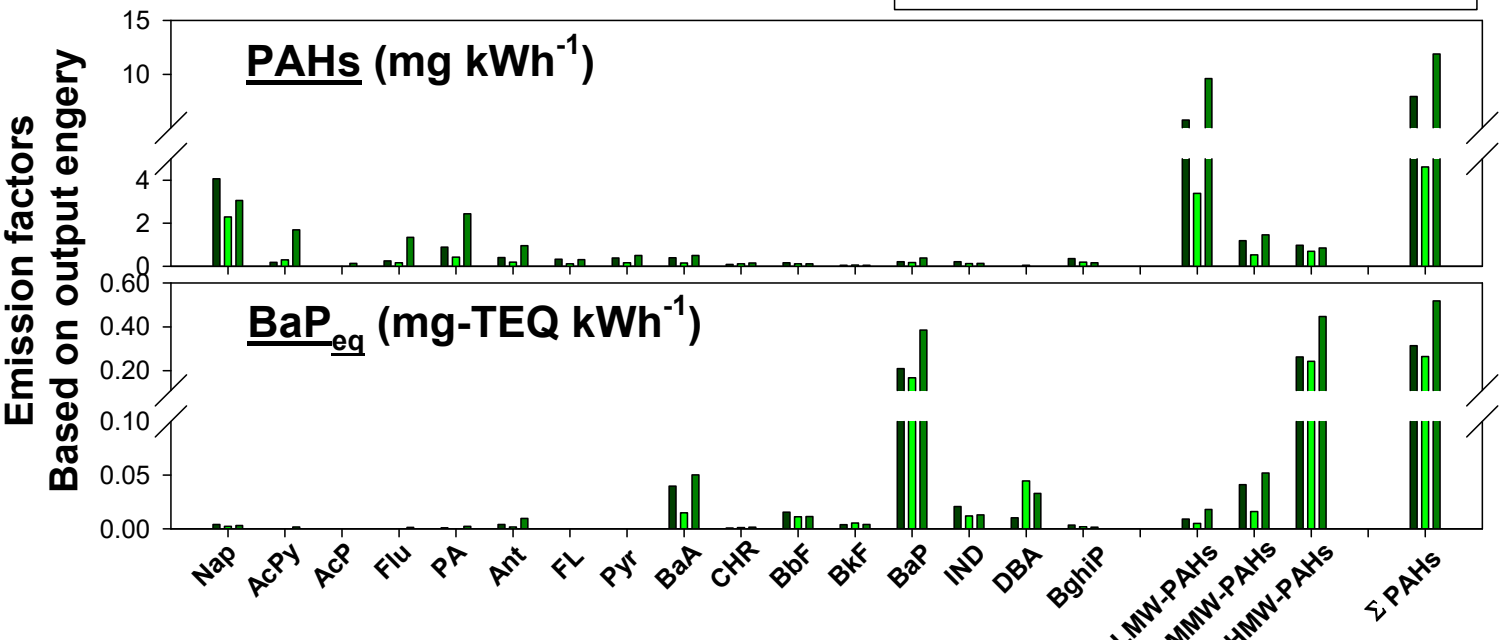

(C) high-load (3.0 kW)

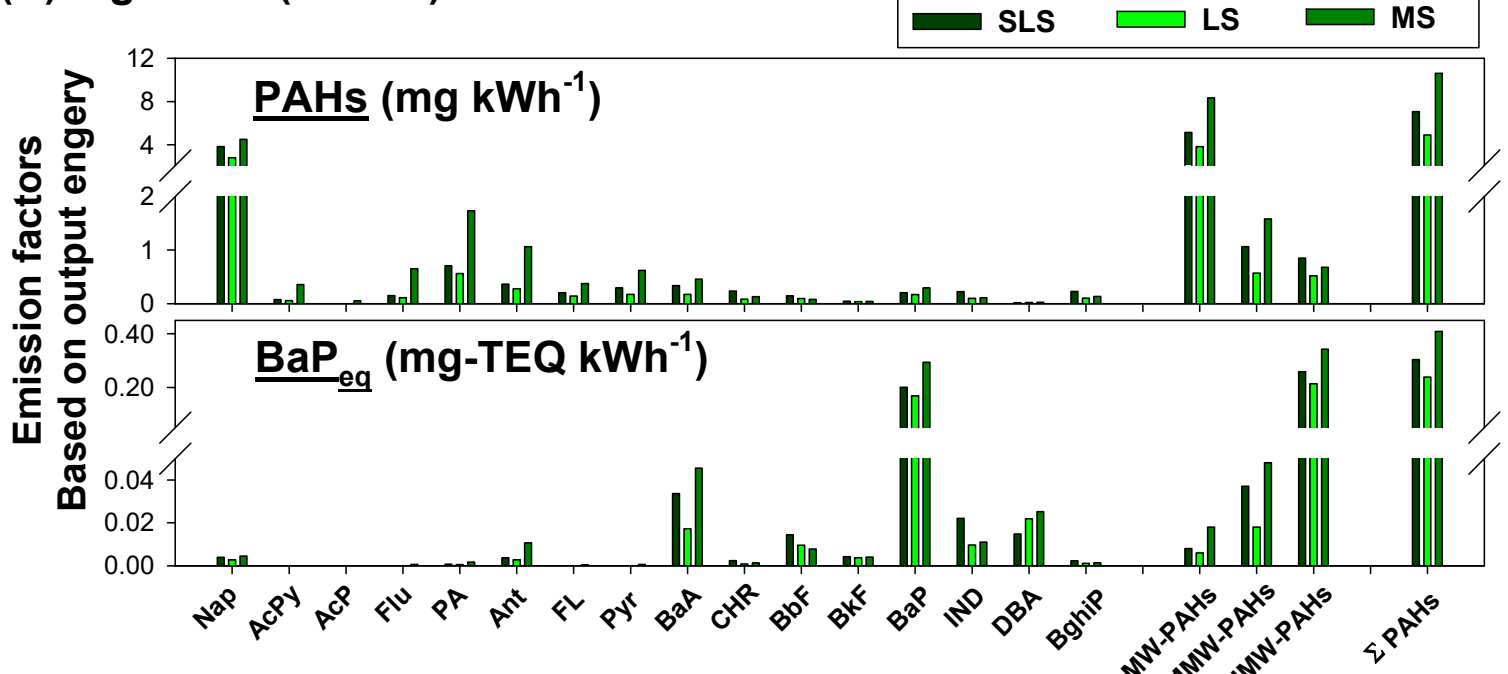

Fig. 8. Emission factors of $\mathrm{PAH}$ and $\mathrm{BaP}_{\mathrm{eq}}$ congeners based on output power emitted from a P2SGE by using SLS, LS, and MS operated at (A) idling $(0 \mathrm{~kW}),(B)$ medium-load $(1.5 \mathrm{~kW})$, and $(\mathrm{C})$ high-load $(3.0 \mathrm{~kW})$. 


\section{ACKNOWLEDGEMENTS}

The authors would like to thank the Ministry of Science and Technology of the Republic of China, Taiwan, for financially supporting this research under Contract No. MOST 107-2221-E-020-001.

\section{REFERENCE}

Abdul-Khalek, I.S., Kittelson, D.B., Graskow, B.R., Wei, Q. and Bear, F. (1998). Diesel exhaust particle size: Measurement issues and trends. SAE Technical Paper No. 980525.

Ålander, T., Antikainen, E., Raunemaa, T., Elonen, E., Rautiola, A. and Torkkell, K. (2005). Particle emissions from a small two-stroke engine: Effects of fuel, lubricating oil, and exhaust aftertreatment on particle characteristics. Aerosol Sci. Technol. 39: 151-161.

Banks, J.L. and McConnell, R. (2015). National emissions from lawn and garden equipment. Presented at the International Emissions Inventory Conference, San Diego, April 16.

Buñuel, E., Marco-Martínez, J., Díaz-Tendero, S., Martín, F., Alcamí, M. and Cárdenas, D.J. (2006). Computational studies on the cyclization of polycyclic aromatic hydrocarbons in the synthesis of curved aromatic derivatives. ChemPhysChem 13: 475-481.

Chuang, S.C., Chen, S.J., Huang, K.L., Wu, E.M.Y., ChangChien, G.P. and Wang, L.C. (2010). Gas/particle partitioning of dioxins in exhaust gases from automobiles. Aerosol Air Qual. Res. 10: 489-496.

Dhital, N.B., Yang, H.H., Wang, L.C., Hsu, Y.T., Zhang, H.Y., Young, L.H. and Lu, J.H. (2019). VOCs emission characteristics in motorcycle exhaust with different emission control devices. Atmos. Pollut. Res. 10: 14981506.

Gehrig, R., Hueglin, C., Deovs, W., Hofer, P., Kobler, J., Stahel, W.A., Baltensperger, U. and Monn, C. (2001). Contribution of road traffic to ambient fine particle concentrations $\left(\mathrm{PM}_{10}\right)$ in Switzerland. Int. J. Veh. Des. 27: 55-64.

Grivas, G., Cheristanidis, S., Chaloulakou, A., Koutrakis, P. and Mihalopoulos, N. (2018). Elemental composition and source apportionment of fine and coarse particles at traffic and urban background locations in Athens, Greece. Aerosol Air Qual. Res. 18: 1642-1659.

Hall, D.E., Doel, R., Jørgensen, R., King, D.J., Mann, N., Scorletti, P. and Heinze, P. (1998). Polycyclic aromatic hydrocarbons in automotive exhaust emissions and fuels. CONCAWE Report 98/55.

Hao, Y., Gao, C., Deng, S., Yuan, M., Song, W., Lu, Z. and Qiu, Z. (2019). Chemical characterisation of $\mathrm{PM}_{2.5}$ emitted from motor vehicles powered by diesel, gasoline, natural gas and methanol fuel. Sci. Total Environ. 674: 128-139.

Jiang, N., Guo, Y., Wang, Q., Kang, P., Zhang, R. and Tang, X. (2017). Chemical composition characteristics of $\mathrm{PM}_{2.5}$ in three cities in Henan, central China. Aerosol Air Qual. Res. 17: 2367-2380.

Lin, C.C., Chen, S.J., Huang, K.L., Hwang, W.I., Chang-
Chien, G.P. and Lin, W.Y. (2005). Characteristics of metals in nano/ultrafine/fine/coarse particles collected beside a heavily trafficked road. Environ. Sci. Technol. 39: 8113-8122.

Lin, C.C., Chen, S.J., Huang, K.L., Lee, W.J., Lin, W.Y., Tsai, J.H. and Chaung, H.C. (2008). PAHs, PAH-induced carcinogenic potency, and particle-extract-induced cytotoxicity of traffic-related nano/ultrafine particles. Environ. Sci. Technol. 42: 4229-4235.

Lin, S.L., Tsai, J.H., Chen, S.J., Huang, K.L., Lin, C.C., Huang, H.T., Hsieh, Y.C. and Chiu, C.H. (2017). Emissions of polycyclic aromatic hydrocarbons and particle-bound metals from a diesel engine generator fueled with waste cooking oil-based biodiesel blends. Aerosol Air Qual. Res. 17: 1579-1589.

Michaels, H. (2012). NONROAD Overview. Presented at the 2012 International Emission Inventory Conference of the US Environmental Protection Agency, Tampa, Florida, August 16.

Nisbet, I.C.T. and LaGoy, P.K. (1992). Toxic equivalency factors (TEFs) for polycyclic aromatic hydrocarbons (PAHs). Regul. Toxicol. Pharmacol. 16: 290-300.

Power, M.C., Kioumourtzoglou, M.A., Hart, J.E., Okereke, O.I., Laden, F. and Weisskopf, M.G. (2015). The relation between past exposure to fine particulate air pollution and prevalent anxiety: Observational cohort study. BMJ 350: h1111.

Shipchandler, R. (2008). VOC emissions from gas powered leaf blowers in the Chicago metropolitan region. Waste Management and Research Center Report. Illinois Waste Management and Research Center, TN08-093.

Tsai, J.H., Ko, Y.L., Huang, C.M. and Chiang, H.L. (2019). Effects of blending ethanol with gasoline on the performance of motorcycle catalysts and airborne pollutant emissions. Aerosol Air Qual. Res. 19: 2781-2792.

Volckens, J., Braddock, J., Snow, R.F. and Crews, W. (2007). Emissions profile from new and in-use handheld, 2-stroke engines. Atmos. Environ. 41: 640-649.

Volckens, J., Olson, D.A. and Hays, M.D. (2008). Carbonaceous species emitted from handheld two-stroke engines. Atmos. Environ. 42: 1239-1248.

Wang, H., Ge, Y., Tan, J., Wu, L., Wu, P., Hao, L., Peng, Z., Zhang, C., Wang, X., Han, Y. and Zhang, M. (2018). The real-world emissions from urban freight trucks in Beijing. Aerosol Air Qual. Res. 18: 1448-1456.

Xiang, S., Hu, Z., Zhai, W., Wen, D. and Noll, K.E. (2018). Concentration of ultrafine particles near roadways in an urban area in Chicago, Illinois. Aerosol Air Qual. Res. 18: 895-903.

Yang, H.H., Chien, S.M., Chao, M.R. and Lin, C.C. (2005). Particle size distribution of polycyclic aromatic hydrocarbons in motorcycle exhaust emissions. J. Hazard. Mater. B125: 154-159.

Yang, H.H., Dhital, N.B., Wang, L.C., Hsieh, Y.S., Lee, K.T., Hsu, Y.T. and Huang, S.C. (2019). Chemical characterization of fine particulate matter in gasoline and diesel vehicle exhaust. Aerosol Air Qual. Res. 19: 14391449.

Zhang, X., Kang, J., Chen, H., Yao, M. and Wang, J. (2018). 
$\mathrm{PM}_{2.5}$ meets blood: In vivo damages and immune defense. Aerosol Air Qual. Res. 18: 456-470.

Zhu, Y., Hinds, W.C., Kim, S., Shen, S. and Sioutas, C. (2002). Study of ultrafine particles near a major highway with heavy-duty diesel traffic. Atmos. Environ. 36: 4323 4335.

Zielinska, B., Sagebiel, J., McDonald, J.D., Whitney, K. and Lawson, D.R. (2004). Emission rates and comparative chemical composition from selected in-use diesel and gasoline-fueled vehicles. J. Air Waste Manage. Assoc. 54: 1138-1150.

Received for review, December 23, 2019

Revised, February 6, 2020

Accepted, February 13, 2020 